\title{
Implications of the altitude of transient 630-nm dayside auroral emissions
}

Article

Published Version

Lockwood, M., Carlson, H. C. and Sandholt, P. E. (1993) Implications of the altitude of transient $630-\mathrm{nm}$ dayside auroral emissions. Journal of Geophysical Research, 98 (A9). pp. 15571-15587. ISSN 0148-0227 doi: https://doi.org/10.1029/93JA00811 Available at https://centaur.reading.ac.uk/38821/

It is advisable to refer to the publisher's version if you intend to cite from the work. See Guidance on citing.

Published version at: http://dx.doi.org/10.1029/93JA00811

To link to this article DOI: http://dx.doi.org/10.1029/93JA00811

Publisher: American Geophysical Union

All outputs in CentAUR are protected by Intellectual Property Rights law, including copyright law. Copyright and IPR is retained by the creators or other copyright holders. Terms and conditions for use of this material are defined in the End User Agreement.

\section{www.reading.ac.uk/centaur}

\section{CentAUR}

Central Archive at the University of Reading 
Reading's research outputs online 


\title{
Implications of the Altitude of Transient 630-nm Dayside Auroral Emissions
}

\author{
M. LOCKWOOD ${ }^{1}$ \\ Rutherford Appleton Laboratory, Space Science Department, Chilton, England \\ H. C. CARLSON JR. ${ }^{2}$ \\ Phillips Laboratory, Hanscom Air Force Base, Bedford, Massachusetts \\ P. E. SANDHOLT \\ Department of Physics, University of Oslo, Oslo, Norway
}

\begin{abstract}
The altitude from which transient 630-nm ("red line") light is emitted in transient dayside auroral breakup events is discussed. Theoretically, the emissions should normally originate from approximately 250 to $550 \mathrm{~km}$. Because the luminosity in dayside breakup events moves in a way that is consistent with newly opened field lines, they have been interpreted as the ionospheric signatures of transient reconnection at the dayside magnetopause. For this model the importance of these events for convection can be assessed from the rate of change of their area. The area derived from analysis of images from an all-sky camera and meridian scans from a photometer, however, depends on the square of the assumed emission altitude. From field line mapping, it is shown for both a westward and an eastward moving event, that the main $557.7-\mathrm{nm}$ emission comes from the edge of the $630 \mathrm{~nm}$ transient, where a flux transfer event model would place the upward field-aligned current (on the poleward and equatorward edge, respectively). The observing geometry for the two cases presented is such that this is true, irrespective of the $630-\mathrm{nm}$ emission altitude. From comparisons with the European incoherent scatter radar data for the westward (interplanetary magnetic field $B_{y}>0$ ) event on January 12,1988 , the $630-\mathrm{nm}$ emission appears to emanate from an altitude of $250 \mathrm{~km}$, and to be accompanied by some 557.7-nm "green-line" emission. However, for a large, eastward moving event observed on January 9,1989 , there is evidence that the emission altitude is considerably greater and, in this case, the only $557.7-\mathrm{nm}$ emission is that on the equatorward edge of the event, consistent with a higher altitude $630-\mathrm{nm}$ excitation source. Assuming an emission altitude of $250 \mathrm{~km}$ for this event yields a reconnection voltage of $>50 \mathrm{kV}$ during the reconnection burst but a contribution to the convection voltage of $>15$ $\mathrm{kV}$. However, from the motion of the event we infer that the luminosity peaks at an altitude in the range of 400 and $500 \mathrm{~km}$, and for the top of this range the reconnection and average convection voltages would be increased to $>200 \mathrm{kV}$ and $>60 \mathrm{kV}$, respectively. (These are all minimum estimates because the event extends in longitude beyond the field-of-view of the camera). Hence the higher-emission altitude has a highly significant implication, namely that the reconnection bursts which cause the dayside breakup events could explain most of the voltage placed across the magnetosphere and polar cap by the solar wind flow. Analysis of the plasma density and temperatures during the event on January 9, 1989, predicts the required thermal excitation of significant 630-nm intensities at altitudes of $400-500 \mathrm{~km}$.
\end{abstract}

\section{INTRODUCTION}

Much recent interest has been focused on transient auroral phenomena seen throughout the dayside, termed "dayside auroral breakup" events [Sandholt et al., 1985, 1989a, b, $1990 a, b, 1992 a, b$, Sandholt, 1988]. Such events can be observed at winter solstice from the Svalbard islands using all-sky cameras and meridian-scanning photometers. Combination of such measurements with data from the European incoherent scatter (EISCAT) radar has shown that they are associated with transient bursts of plasma flow and electron and ion heating [Lockwood et al., 1989a, b, 1990a, b, c] .

\footnotetext{
${ }^{1}$ Also visiting honorary lecturer at Imperial College, London, England.

${ }^{2}$ At Rutherford Appleton Laboratory as part of the European Office of Aerospace Research and Development (EOARD) Window on Europe Programme.
}

Copyright 1993 by the American Geophysical Union.

Paper number 93JA00811. 0148-0227/93/93JA-00811\$05.00
Lockwood et al. $[1989 a, b]$ have pointed out that the pattern of motion of these events is one of zonal motion around the polar cap boundary, followed by poleward motion into the polar cap, and that this is consistent with the expected behavior of newly opened field lines for a nonzero interplanetary magnetic field (IMF) $B_{y}$ component. This is because the initially dominant action of magnetic tension decays and magnetosheath flow becomes more important as the newly opened flux tube evolves. Furthermore, events observed from Svalbard move eastward when the IMF $B_{y}$ is negative but westward when it is positive [Sandholt, 1988; Sandholt et al., 1992a]. This behavior is nearly always explained in terms of the magnetic tension on newly reconnected field lines. The only other explanation suggested to date postulates a $B_{y}$-dependent shift in the MLT of the location where a solar wind dynamic pressure pulses impact upon the magnetosphere [Sibeck, 1990]. However, analysis of large traveling convection vortices, thought to be caused by solar wind dynamic pressure changes, shows them to always originate from near magnetic noon, independent of the sense of $B_{y}$ [Sibeck, 1993]. In addition, the pressure 
$\mathrm{B}_{z}<0 ; \mathrm{B}_{\mathrm{y}}>0 ; \mathrm{N}$. hemisphere

a)

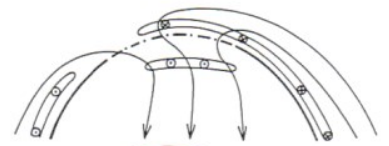

b)

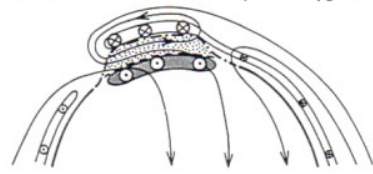

c)

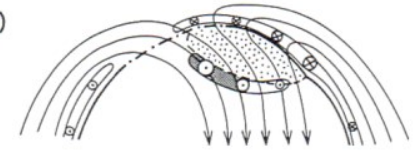

d)

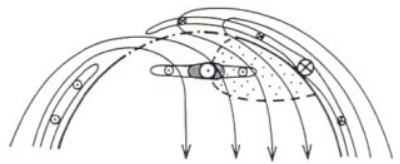

- adiaroic open/closed boundary

- - - merging gap

---- edge of flux opened by F.T.E.
$\mathrm{B}_{z}<0 ; \mathrm{B}_{\mathrm{y}}<0 ; \mathrm{N}$. hemisphere

e)

f)
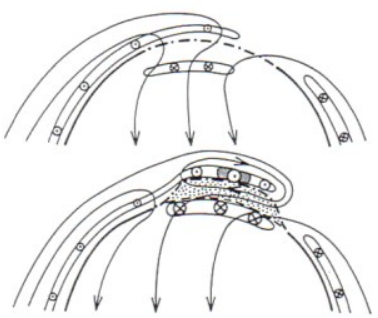

g)

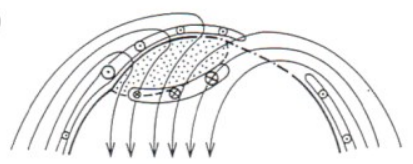

h)
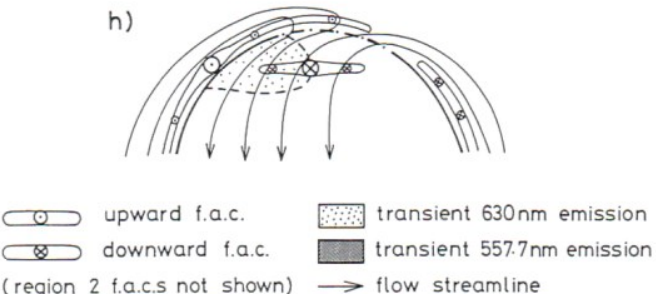

Fig. 1. Schematic of the motion of dayside breakup events, showing a sequence of snapshots, roughly 3 min apart, of the locations of field-aligned currents and $630 \mathrm{~nm}$ and $557.7 \mathrm{~nm}$ auroral transients for $(a)$ IMF $B_{y}>0$ and $(b) B_{y}$ $<0$ in the Northern hemisphere (adapted from Smith and Lockwood, 1990). Also shown are the corresponding plasma flows (adapted from Cowley et al. [1991]). For clarity, the region 2 field-aligned currents have been omitted.

pulse model predicts the phase motion of a vortical plasma flow pattern away from the point of impact, rather than a bulk plasma flow, as observed during dayside breakup events [e.g., Sandholt et al., $1990 a, b$ ].

Other evidence that dayside breakup events are ionospheric signatures of transient reconnection bursts comes from the similarities to the behavior of magnetopause flux transfer events (FTEs), which are thought to be the magnetopause signatures of such bursts [Russell and Elphic, 1978, 1979; Haerendel et al., 1978; Paschmann et al., 1982; Berchem and Russell, 1984; Rijnbeek et al., 1984; Farrugia et al., 1987a , b , 1988; Lockwood, 1991]. The FTE events occur almost exclusively when the IMF is southward [Berchem and Russell, 1984], when they repeat quasiperiodically with a range of repetition periods between about 2 and 20 min [Elphic, 1988; Lockwood and Wild, 1993], with a mean value of about $8 \mathrm{~min}$ [Rijnbeek et al., 1984]. This behavior is very similar to that found for the dayside breakup events [Lockwood et al., 1989b]. Furthermore, Elphic et al. [1990] have shown that in the only example of the required simultaneous magnetopause and ionospheric observations, dayside breakup events did follow magnetopause FTEs with the expected delay [see Sandholt et al., 1992b].

\subsection{FTE Signatures and the Pulsating Cusp Concept}

On the basis of these observations, Smith and Lockwood [1990] have proposed that the transient auroral event seen in the $630-n m$ oxygen red-line emissions is caused by cusp electron precipitation down the newly opened field lines. In this case, the variations in reconnection rate produced a pulsed cusp. The transient 557.7-nm oxygen green emission is, in their model, identified with the region of the transient, filamentary upward field-aligned current associated with the motion of the newly opened flux. Figure $1 a-1 d$ adapted from Smith and Lockwood, shows the evolution of a northern hemisphere transient event for IMF $B_{y}>0$. While the event moves westward under the magnetic tension, the upward field-aligned current (of the oppositely directed pair of currents required to transfer the momentum to the ionosphere) is situated on the poleward edge of the red-line transient. Sandholt et al. [1990b] have shown that the 557.7-nm arc fragments are colocated with the inferred position of this field-aligned current, for such an event. Figures $1 e-1 h$ show the corresponding sequence, for a northern hemisphere event with IMF $B_{y}<0$. In this case the event moves initially eastward under magnetic tension, requiring the upward field-aligned current to be on the equatorward edge of the patch of newly opened field lines. Because this current is again associated with the $557.7-\mathrm{nm}$ emission, the greenline auroral transient appears at the equatorward edge of the red-line event in this case. (Note that in the southern hemisphere, Figures $1 a-1 d$ would be expected to apply for IMF $B_{y}<0$ and Figures $1 e-1 h$ for $B_{y}>0$ ).

Figure 1 also shows schematically the variations in the plasma flows expected during these events. These flows are predicted using the concept of flow excitation developed by Cowley and Lockwood [1992] from high time resolution observations of the response of dayside convection to IMF changes. This model is based on the idea that convection is excited following a burst of reconnection only while the magnetosphere-ionosphere system tends toward its equilibrium configuration for the new amount of open flux. The time scale for this, and hence also of the decay of the enhanced flow, is found by both experiment and theory to be about 
10-15 min. Cowley et al. [1991] and Smith et al. [1992] have used this model to predict the ionospheric signatures of FTEs and the corresponding morphology of cusp ion precipitation (the "pulsating cusp"' model).

In order to explain the behavior of the associated plasma flows, here we discuss only the IMF $B_{y}>0$, northern hemisphere case shown in Figures $1 a-1 d$. Corresponding arguments can be applied to the case shown in Figures $1 e-1 h$. Figure 1 shows the effect of a single square wave pulse of the dayside reconnection voltage. This pulse is superposed on a background reconnection voltage of $3 \Delta$, where $\Delta$ is the separation of the flow equipotentials shown in Figure 1. The pulse is considered to last $\Delta t=2 \mathrm{~min}$, during which the reconnection voltage rises to $9 \Delta$. The sequence shown is considered to cover $12 \mathrm{~min}$, over which period the average reconnection voltage is therefore $4 \Delta$.

Figure 1 shows both of the two possible classifications of the open/closed field line boundary in the ionosphere. The first is a merging gap (shown as a dot-dashed line), at which closed flux is converted into open flux. By definition, therefore, this is the ionospheric projection of the reconnection $\mathrm{X}$ line, along which the reconnection voltage is applied. At all other points, the boundary is "'adiaroic"' (this term, meaning "'not flowing across," was introduced by Siscoe and Huang [1985]), as shown by the continuous solid line. The convection streamlines cross an adiaroic boundary which is moving in the Earth's frame (although the flux tubes do not); only if the boundary is stationary in the Earth's frame do the streamlines only cross the boundary at the merging gap [Lockwood and Cowley, 1992]. The latter is the case in Figure $1 a$, which shows some background, steady state flows driven by the background reconnection voltage $3 \Delta$ before the pulse of increased voltage. Figure $1 b$ shows the situation 3 min later, during the burst of enhanced reconnection. At this time the voltage along both the magnetopause $\mathrm{X}$ line and the ionospheric merging gap, in their own rest frames, is $9 \Delta$. However, Figure $1 b$ the voltage along the merging gap in the Earth's frame remains at $3 \Delta$ because the merging gap is moving equatorward in response to the enhanced reconnection. The only increased flows at this time arise because of the magnetic tension force on the newly opened flux. Because this case is for a positive IMF $B_{y}$ and the northern hemisphere, the tension force results in the FTE signature (and the plasma within it) moving westward around the polar cap boundary.

After a further $3 \mathrm{~min}$, the reconnection pulse is over, but the flows are enhanced, as shown in Figure $1 c$. The voltage associated with the flow streamlines which cross the dayside open/closed boundary is now $6 \Delta$ (twice that in Figure $1 a$ ). Half of this is associated with the ongoing reconnection at the background voltage of $3 \Delta$. The other half is associated with the poleward return of the open/closed boundary which commences as soon as the enhanced reconnection pulse ends. Note that the flow streamlines cross the poleward moving adiaroic polar cap boundary to the west of the merging gap. Hence at this time the region of flow entry into the polar cap is considerably broader than the merging gap in its local time extent. The process is almost complete after a further 3 min Figure $1 d$, for which the boundary has almost returned to its equilibrium position and is moving more slowly poleward. The flow voltage is $4 \Delta$. Three minutes later, the system will have effectively returned to the background, steady state shown in Figure $1 a$.
Averaged over the whole period of $12 \mathrm{~min}$, the flow voltage is $4 \Delta$. This is the same as the average reconnection voltage for the same period. However, at any one instant of time, the flow and reconnection voltages are not equal because of the latitudinal motion of the merging gap.

In this model, the application of a pulse of reconnection voltage causes the merging gap to move equatorward without necessarily causing any flow. To quantify the likely merging gap motion, consider a large reconnection pulse of $225 \mathrm{kV}$, lasting $2 \mathrm{~min}$ (over the $12 \mathrm{~min}$ considered here, such a pulse would contribute $37.5 \mathrm{kV}$ to convection). Such a pulse would reconnect a total of $2.7 \times 10^{7} \mathrm{~Wb}$, which for a merging gap length of $1500 \mathrm{~km}$ (and in the absence of any enhanced plasma flow), would require the merging gap to migrate equatorward by $360 \mathrm{~km}$ (that is, about $3^{\circ}$ of latitude). In practice, the merging gap may not move quite so far, in which case some poleward flow will be excited at this time. For example, were the merging gap to move only $300 \mathrm{~km}$, an average poleward flow of $(360-300) /(2 \times 60)=0.5 \mathrm{~km} \mathrm{~s}^{-1}$ would be driven during the reconnection pulse. After the reconnection pulse, poleward flow is excited as the merging gap returns poleward to its equilibrium location. If this proceeds at a constant speed for $10 \mathrm{~min}$, as discussed above, this yields a poleward speed of the now inactive merging gap (that is, it is now adiaroic) of $300 /(10 \times 60)=0.5 \mathrm{~km} \mathrm{~s}^{-1}$, which would also be the poleward plasma flow speed. Hence this example would give sawtooth oscillations in the latitude of the merging gap (of amplitude $3^{\circ}$ ), but a constant poleward flow of $0.5 \mathrm{~km} \mathrm{~s}^{-1}$. Such motions of the merging gap were invoked by Lockwood and Smith [1989] to explain a cusp intersection by the DE 2 satellite as an ionospheric signature of an FTE. Indeed, Lockwood and Smith [1992] have recently used cusp spectrograms to show that the reconnection proceeded as a series of pulses of exactly the kind invoked above.

This simplistic case has been discussed here to illustrate the idea that pulsed reconnection does not necessarily give pulsed flow in the dayside ionosphere. The oscillatory merging gap latitude could result in constant dayside convection if the IMF $B_{y}$ were small in magnitude. In practice, some variations in the flow (with the same period as the reconnection pulses) are likely to be present but may be small enough to evade detection. If the IMF $B_{y}$ component is large in magnitude, east/west flow pulses would be expected, as a result of the magnetic tension on the newly opened flux. The observed cases of strong flow bursts, in conjunction with dayside breakup auroral transients, do show eastward or westward flow and are for strongly negative or positive IMF $B_{y}$, respectively [e.g., Lockwood et al., 1989b].

Figure 1 and the above discussion consider one isolated pulse of reconnection followed by sufficient time for equilibrium to be largely reestablished. Observations of magnetopause FTEs indicate that reconnection pulses tend to recur with a mean interval of $\Delta \tau=8 \mathrm{~min}$, when the IMF is southward. Lockwood and Wild [1993] have presented the distribution of inter-FTE periods, showing that in the majority $(>80 \%)$ of cases, an event will recur within $10 \mathrm{~min}$ of the preceding one. This period is considered significant here because it is roughly the minimum time scale on which the magnetosphere-ionosphere system returns to an equilibrium state following a pulse of reconnection. (In addition, it is roughly the time following reconnection for which "cusp" magnetosheath plasma will precipitate to low altitudes down 
a newly opened field line). Hence in general, a second reconnection event will perturb the system before the flow excited by the previous event has fully subsided, (and the cusp precipitation within the event has turned into the lower flux, lower-energy "mantle" precipitation). Hence more than one "active" event is likely to exist at any one instant. Figure 1 studies the more unusual case of an isolated reconnection pulse, only in order that the behavior of the system be more clearly demonstrated.

Hence in general, we would expect a second reconnection pulse before the merging gap has had time to retreat to its equilibrium location following the proceeding one. Hence the merging gap will show an equatorward trend consisting of rapid equatorward motions during the reconnection pulses and only partial, slower poleward returns during the interpulse intervals. This dayside erosion would continue throughout a substorm growth phase. Averaged over one growth phase, M. Lockwood (Transpolar voltage, convection, and the substorm cycle, submitted to the Journal of Geophysical Research, 1993) has found that the dayside flow voltage was equal to roughly half the reconnection voltage, the other half resulting in the equatorward motion of the merging gap [see Lockwood and Cowley, 1992]. This equatorward motion is interrupted by the onset of significant reconnection in the magnetotail after onset of the substorm expansion phase.

\subsection{Evaluation of the Importance of Transient Events to Convection}

Lockwood et al. [1990b] have pointed out that, with the above interpretation, the importance of these events to magnetospheric and ionospheric convection depends upon how much flux is reconnected by each burst. Because the ionosphere can, to a good order of approximation, here be considered to be incompressible (that is, the ionospheric field strength, $B_{i}$, is constant), the amount of newly reconnected flux $\Delta F$ can be estimated from the area of the event A to be $\left(A \times B_{i}\right)$. If the event forms in a time $\Delta t$ (the duration of the burst of reconnection), the mean reconnection voltage in the burst is $(\Delta F / \Delta t)$. However, if the events repeat periodically with a period $\Delta \tau$, the amount of flux reconnected by the burst in each cycle of this length is still only $\Delta F$. Hence the average contribution of the bursts to the convection voltage is $(\Delta F / \Delta \tau)$.

Lockwood et al. [1990b] estimated the spatial dimensions of the events by assuming that the region of newly opened flux is convected past the meridian scanned by the EISCAT radar and the Svalbard photometers, without changing shape or size. From a survey of 12 events, they found that the events were typically $300 \mathrm{~km}$ in north-south extent, but were extended along the $L$ shells, having a typical east-west dimension of $1500 \mathrm{~km}$. Assuming a crude elliptically shaped patch, this yields an area of $A=5 \times 10^{11} \mathrm{~m}^{2}$ and a flux of $\Delta F \approx 2.5 \times 10^{7} \mathrm{~Wb}$. Magnetopause FTE observations typically last $2 \mathrm{~min}$ [Elphic, 1988], and if the events have not changed in size while moving between the reconnection $\mathrm{X}$ line and the satellite, this is the duration of the reconnection burst required $(\Delta t)$. For this value, the mean reconnection voltage in the bursts is $(\Delta F / \Delta t) \approx 200 \mathrm{kV}$, but for the mean repetition period $\Delta \tau$ of $8 \mathrm{~min}$, the average voltage over each cycle is $(\Delta F / \Delta \tau) \approx 50 \mathrm{kV}$.

High time resolution images of the $630-\mathrm{nm}$ transients are now available from a CCD all-sky cameras [e.g., Sandholt et al., 1990b, 1992a]. These images could be used to calculate the area of the events $A$ if the emission profile and, in particular, the altitude of peak emission were known. The camera records the intensity of $630-\mathrm{nm}$ emissions from a slant path along each azimuth and elevation. For an assumed emission altitude, $h$, an area can be computed for any region from the images obtained. However, the derived north-south and east-west dimensions and velocities of the events are all proportional to $h$, and the area $A$, flux $\Delta F$, and the peak and average reconnection voltages are proportional to the square of $h$. Thus far, it has not been possible to make simultaneous observations of any one such event from two sites, and hence the emission altitude has not been determined empirically. From the foregoing, we conclude that accurate values of $h$ are vitally important. This paper discusses the altitude from which the $630-\mathrm{nm}$ transients arise and its implications. After a brief discussion of the uncertainty concerning the emission altitude in section 2, section 3 studies in detail two dayside breakup events, one moving eastward the other moving westward (as previously discussed by Lockwood et al. [1990c] and Sandholt et al. [1990b], respectively).

\section{Profile of 630-nm Emissions}

To date, no simultaneous observations of unambiguously the same $630-\mathrm{nm}$ dayside auroral transient have been reported from two observing sites. Hence the emission altitude in these events has yet to be measured directly. Theoretically, there is considerable uncertainty over this height. It is interesting to note that in his pioneering work on triangulation measurements of the altitude of maximum auroral luminosity, Stömer [1955] recorded a considerable number of cases, where the peak luminosity was in the range of $300-500 \mathrm{~km}$. In this section we discuss how significant 630-nm emissions could arise from great altitudes.

The major source of uncertainty in anticipating the height from which the $630-\mathrm{nm}$ emissions will be most intense, derives from the variability of the electron gas temperature $T_{e}$. Very high values of $T_{e}$ can elevate the altitude at which peak 630 -nm emissions will occur to between $400-600 \mathrm{~km}$. An appreciable source of uncertainty stems from variability in the fraction of the incident precipitating flux which is relatively soft (meaning of energy below roughly $100 \mathrm{eV}$ ). For instance, $25-100 \mathrm{eV}$ electrons incident from above stop between $300-400 \mathrm{~km}$ altitude, while electrons with incident energies greater that $0.5 \mathrm{keV}$ penetrate to below $200 \mathrm{~km}$ altitude. An additional consideration is that local thermospheric heating can lead to localized increases in the altitude of a given neutral atmospheric pressure level, as well as localized enhancements or depletions in density and changes in the $\mathrm{O} / \mathrm{N}_{2}$ density ratio by a few tens of percentage. Auroral workers generally assume a nominal 630-nm emission altitude near $250 \mathrm{~km}$, based on the rapid increase of quenching much below that height, and the usual ratios of auroral electron fluxes near and above $1 \mathrm{keV}$ to those around and below $0.1 \mathrm{keV}$. The above considerations mean that the height of a given peak 630-nm emission event in the cusp region of soft electron precipitation could be a factor of about 2 greater than the frequently assumed value of $250 \mathrm{~km}$.

\subsection{Precipitating Electron Impact Excitation}

The $630-\mathrm{nm}$ emission arises when an electron in the ${ }^{1} \mathrm{D}$ state of an oxygen atom falls to a lower energy level. The 
altitude of excitation of this $O\left({ }^{1} \mathrm{D}\right)$ state by precipitating electron impact is critically dependent on the energy of the incident electrons. This is because of the strong energy dependence of the collision cross sections, the consequent altitude of unity optical depth, and thus the depth of penetration of the incident electrons. Very soft electrons, with incident energies between $25-100 \mathrm{eV}$, are stopped between $300-400 \mathrm{~km}$ [Mantas and Walker, 1976]. This is the altitude range within which most of their energy deposition occurs and within which most of the associated $O\left({ }^{1} \mathrm{D}\right)$ excitation occurs. For energies above $500 \mathrm{eV}$, most of the precipitating electron energy deposition (and $\mathrm{O}\left({ }^{1} \mathrm{D}\right)$ excitation) is below $200 \mathrm{~km}$ altitude. The efficiency of excitation of the $O\left({ }^{1} \mathrm{D}\right)$ state, per unit incident energy, also depends on how hard or soft the incident electron flux is. Lower-energy electrons, which stop at higher altitudes where the $\mathrm{O} / \mathrm{N}_{2}$ density ratio is greater, lose their energy to air that is relatively oxygen rich. This leads to relatively more $O\left({ }^{1} \mathrm{D}\right)$ excitation. The number of $630-\mathrm{nm}$ photons emitted per $O\left({ }^{1} \mathrm{D}\right)$ excitation is also significantly greater at higher altitudes. The long (about $2 \mathrm{~min}$ ) mean lifetime of the $\mathrm{O}\left({ }^{1} \mathrm{D}\right)$ state of atomic oxygen gives deexcitation by collisions, before 630 -nm photons are emitted. The density of $\mathrm{N}_{2}$, which is primarily responsible for this quenching the $O\left({ }^{1} \mathrm{D}\right)$ state, falls with roughly twice the scale height of the $O$. More than $90 \%$ of the excited $O\left({ }^{1} \mathrm{D}\right)$ yield $630-\mathrm{nm}$ emissions near and above $350 \mathrm{~km}$. This yield falls to an order of $10 \%$ near $225 \mathrm{~km}$ [e.g., Wickwar et al., 1974] and continues to fall rapidly with decreasing altitude. Consequently, a given energy flux, carried by electrons soft enough to stop near $350 \mathrm{~km}$, will be over 10 times as effective at producing $630 \mathrm{~nm}$ than if it had a sufficiently higher characteristic energy to penetrate to below $225 \mathrm{~km}$.

The quenching is very severe below about $200 \mathrm{~km}$, yet usually little impact excitation of the $O\left({ }^{1} \mathrm{D}\right)$ state occurs above about $300 \mathrm{~km}$. Consequently, researchers frequently assume an altitude near $250 \mathrm{~km}$ for the peak $630-\mathrm{nm}$ emission at auroral latitudes. However, the high-altitude cutoff is, in fact, a consequence of the auroral electron energy spectrum. The intensity of the low $(\leq 0.1 \mathrm{keV})$ energy portion of the precipitating electron energy flux, relative to the normally higher flux of the electron precipitation at higher energies, determines the decrease of the $O\left({ }^{1} D\right)$ excitation with increasing altitude. One should note that the electron precipitation in the cusp region typically consists of particles with energy that is lower than elsewhere in the auroral region; electron energies are generally tenths of a $\mathrm{keV}$ rather than the several $\mathrm{keV}$ found elsewhere in the auroral oval. Characteristic energies as low as tens of electron volts have been measured. The consequence for emission altitude is important. A decrease in characteristic energy to $20-30 \mathrm{eV}$ from $200-300 \mathrm{eV}$ can raise the $630-\mathrm{nm}$ emission peak by about 100 $\mathrm{km}$, yet it is not straightforward to characterize how representative such low energies may be of cusp precipitation in general. There is experimental difficulty in measuring electron fluxes with such low energies, because of variable spacecraft changing. However, Fontheim et al. [1987] concluded that the $1-$ to $10-\mathrm{eV}$ component of the precipitation was greatly enhanced when very high ionospheric electron temperatures were observed by the DE 2 satellite.

It is widely agreed that electron precipitation leads to excitation of $\mathrm{O}\left({ }^{1} \mathrm{D}\right)$ and $630 \mathrm{~nm}$ emission by several processes and that direct electron impact excitation by second- ary electrons or by very low energy primaries are not the only mechanisms [e.g., Rees and Roble, 1986]. This is largely because the $O\left({ }^{\prime} D\right)$ excitation threshold is so low $(1.96 \mathrm{eV})$. However, for our purposes it is sufficient to note that with the exception of the thermal electron excitation term discussed in the next section these all peak at comparable altitudes. This altitude is near the neutral pressure level of unity optical depth for the characteristic energy of the incident auroral electrons in question. Note that an intense flux of soft auroral electrons will lead to rapid heating of the electron gas on the same flux tubes as the auroral electron impact emission. Thus the precipitating electrons produce both thermal and impact excitation on the same flux tube. However, the emission altitude for the thermal excitation is, potentially, much higher than for the impact excitation.

\subsection{Thermal Electron Excitation}

Because $O\left({ }^{1} D\right)$ has such a low threshold of energy excitation $(1.96 \mathrm{eV})$, it can be excited by the high-energy tail of a thermal electron gas of sufficiently high temperature. The steep increase of excitation cross section with energy just above $2 \mathrm{eV}$, make the thermal electron impact component of $630 \mathrm{~nm}$ critically dependent on the electron gas temperature, $T_{e}$. As $T_{e}$ increases from 2000 to $4000 \mathrm{~K}$, the rate of $\mathrm{O}\left({ }^{1} \mathrm{D}\right)$ excitation increases by $2 \frac{1}{2}$ orders of magnitude. The absolute $630-\mathrm{nm}$ emission rate depends on the number of thermal electrons, times the number of atomic oxygen atoms with which they could collide, with allowance for quenching. For representative conditions in the cusp, an increase in $T_{e}$ at $500 \mathrm{~km}$ from $3000 \mathrm{~K}$ to $4000 \mathrm{~K}$, causes a tenfold increase in the $630-\mathrm{nm}$ emission, from an order of $0.1 \mathrm{kR}$ to an order of $1 \mathrm{kR}$.

Indirect experimental evidence supports the suggestion that thermal excitation can be important in the cusp. Electron gas temperatures which were sufficiently high to excite significant 630-nm emission have been measured at Sondrestromfjord, [Wickwar and Kofman, 1984], on the Dynamics Explorer 2 [Brace et al., 1982], and over Svalbard, as viewed by EISCAT by the Polar Experiment (see section 3.2).

A theoretical or modelling consideration of the intensity and altitude of this thermally excited $630-\mathrm{nm}$ emission is, essentially, an electron gas thermal balance consideration. The question is whether we should expect a sufficiently high $T_{e}$ at an altitude where a sufficiently great electron concentration $N_{e}$ coexists with a sufficiently large atomic oxygen concentration, such that the rate of collisional excitation of $O\left({ }^{1} \mathrm{D}\right)$ will lead to $630-\mathrm{nm}$ emission with kilorayleigh intensities.

It is beyond the scope of this paper to carry out a full thermal balance computation. However, a discussion of the processes and order of the terms prove most useful. The reader is referred for a full quantitative analysis to a parametric study of specific absorption rate ares by Kozyra et al. [1990]. Much of the physics applicable to SAR arcs can be applied to the dayside $630-\mathrm{nm}$ transients, aside from the different source of the electron gas heating. We here give a simple qualitative description of the important points.

At the onset of a flux of precipitating electrons, into the optically thin topside ionospheric electron gas (of density $N_{e}$ ), the ambient electron gas temperature $T_{e}$ will start to increase at all altitudes. The initial rate of increase will depend on the incident electron flux but not on $N_{c}$ (the 
collision cross section and the heat capacity both increase with $N_{e}$, and their effects tend to cancel). A flux of electrons of energy of order tens of electron volts, which is intense enough to produce 630 -nm luminosity of the order of Kilorayleigh intensity, will initiate a $T_{e}$ increase at a rate of about $10^{3} \mathrm{~K}$ per minute. This is an upper limit that neglects subsequent electron gas energy loss. Since background magnetospheric electron heat fluxes maintain $T_{e}$ values near $500 \mathrm{~km}$ of $2000-3000 \mathrm{~K}$ in quasi-steady state, the electron gas cooling rate is a key consideration.

For low-electron densities $\left(N_{e}<3 \times 10^{5} \mathrm{~cm}^{-3}\right)$ and temperatures $\left(T_{e}<3 \times 10^{3} \mathrm{~K}\right)$, the electron gas cools mainly by electron gas heat conduction down magnetic field lines. Near about $200 \mathrm{~km}$, electron-neutral collisions maintain the electron gas in close thermal contact with the neutral particle gas. Thus $T_{\ell}$ decreases monotonically with decreasing height and the shape of the altitude profile of $T_{e}$ is essentially given by the heat conduction equation. In equilibrium, the $T_{e}$ gradient at any height is just that which conducts heat downward at the rate which heat conducts from above, less the local volume cooling or heating rate. Thus the greater the heat flux, the greater the $T_{e}$ and altitude gradient of $T_{e}$ at any height.

'The rate of electron gas cooling to the ion gas (that is, the rate of decrease of energy density of the electron gas) is proportional to the number of electrons available for collisions, times the number of ions available to collide with, that is, to $N_{e}^{2}$. The rate of decrease of the electron temperature $T_{e}$ is therefore proportional to $N_{e}$. Near the height of maximum $N_{e}, h_{\max }$, the electron cooling by this mechanism depends critically on $N_{e}$. Specifically, cooling to ions is unimportant for $N_{e}$ much less than about $3 \times 10^{5} \mathrm{~cm}^{-3}$, whereas it is dominant for $N_{e}$ considerably greater than this value. Thus the value of maximum $N_{e}$ determines whether $T_{e}$ is reduced to the neutral gas temperature near $200 \mathrm{~km}$ or is just reduced to the ion temperature near the greater altitude of $h_{\max }$. This has great implications for whether $T_{e}$ near $400-500 \mathrm{~km}$ can approach high enough values to thermally excite 630-nm emission or is drawn down much closer to the thermospheric temperatures, which would not yield such strong thermal excitation of the $O\left({ }^{1} D\right)$ state. Examination of the quantitative modeling by Kozyra et al. [1990] reveals the following simple argument. When $T_{e}$ at $h_{\max }$ is near $4000 \mathrm{~K}$, and values of $N_{e}$ are high enough to expect $d T_{e} / d h$ to be about $5 \mathrm{~K} / \mathrm{km}, 630$-nm luminosity of an order of kilorayleigh intensity will arise near $500 \mathrm{~km}$, especially when the altitude of maximum $N_{e}, h_{\max }$, is near or above $350 \mathrm{~km}$.

We can summarize the foregoing discussion with three broad statements.

1. When the characteristic energy of the auroral precipitating electrons exceeds $0.6 \mathrm{keV}$, a peak $630-\mathrm{nm}$ emission near, or a little below, $250 \mathrm{~km}$ is expected.

2. When the characteristic energy is $25-100 \mathrm{eV}$, the emission altitude may be expected to be between 300 and 400 $\mathrm{km}$.

3. When $T_{e}$ exceeding $3500 \mathrm{~K}$ is present near $400-500$ $\mathrm{km}$, peak emission altitudes near $500 \mathrm{~km}$ are expected, especially when the $T_{e}$ altitude gradient is large and the $F_{2}$ peak is at high altitudes.

\subsection{Mapping 630-nm Luminosity}

Figure 2 shows the implications of the emission altitude for the deduced latitude of the luminosity for observations

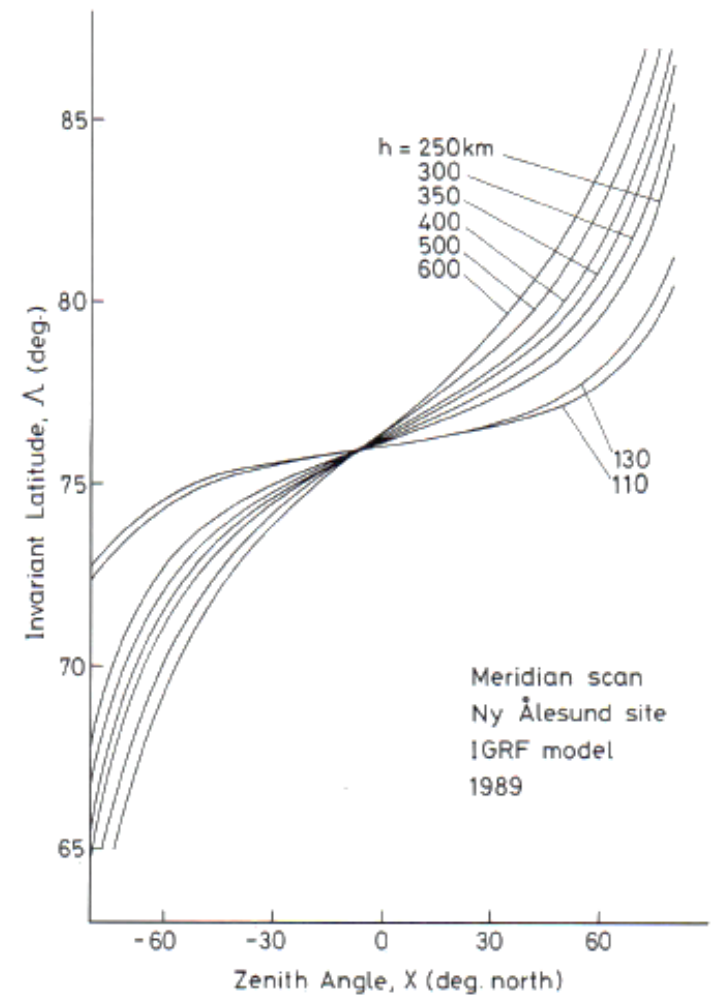

Fig. 2. The invariant latitude $\Lambda$ as a function of zenith angle at Ny Allesund, $\chi$, (defined as positive to the north) for the magnetic meridian scanned by the photometers. Plots are shown for the possible 630-nm emission altitudes of $h=250,300,350,400,500$, and $600 \mathrm{~km}$ as well as for the possible $557.7-\mathrm{nm}$ emission altitudes of 110 and $130 \mathrm{~km}$.

along the magnetic meridian through Ny Ålesund, Svalbard. The plot shows the invariant latitude, as a function of the zenith angle $\chi$, defined as positive to the north. The yalues have been calculated using the International Geomagnetic Reference Field model, with constants appropriate to 1989. The plot is for the same azimuth as employed by the meridian-scanning photometers at Ny Ålesund, namely $29.5^{\circ}$ west of north for $\chi>0$ (and $150.5^{\circ}$ east of north for $\chi<0$ ). Figure 2 shows the curves for various values of the emission altitude $h$; as discussed above, the curves for $250-600 \mathrm{~km}$ are relevant to the 630 -nm emissions. Also shown are the curves for $h$ of $110 \mathrm{~km}$ and $130 \mathrm{~km}$, which cover the expected range of emission altitudes for the 557.7-nm aurora. All curves show approximately the invariant latitude of Ny Allesund $\left(75.8^{\circ}\right)$ at $\chi$ of $-7^{\circ}$, when the instrument points up the field line. Away from this direction, the invariant latitude deduced for a given observation is strongly dependent on the emission altitude assumed. It can be seen that the likely variations in the altitude of the 557.7-nm emissions cause very little variation in the derived invariant latitude, especially at zenith angles below $45^{\circ}$. As most of the $557.7 \mathrm{~nm}$ discussed here was taken at $\chi$ below this value, these differences are here neglected and all 557.7-nm emissions mapped with an assumption of $h=110 \mathrm{~km}$.

Naturally, 630-nm emissions will, in practice, arise from a considerable range of altitudes around the height of peak emission. This spread will have little effect on the inferred latitude of the edge of a patch of 630-nm luminosity, provided that edge is close to zenith. 
However, the spread in altitudes causes two effects at greater magnitude of the zenith angle. Emissions from below the altitude of peak emission will cause some luminosity to appear to arise from further away from the optical instrument than is really the case, if the data are analyzed assuming all luminosity comes from the peak emission height. However, the instrument records the intensity of 630 -nm emission, integrated along the slant path through the feature, and this will increase continuously with decreasing $|\chi|$ for those slant paths which intersect the edge of the 630 -nm patch. Hence the latitude of the edge derived will depend on the 630 -nm isophote (intensity contour) chosen to delineate the feature in question. Depending on that choice of isophote, the latitude of the edge derived can be greater or smaller than that derived by the simple assumption of a single emission altitude. The precise magnitude of this uncertainty depends upon the three-dimensional distribution of emission rate and on the relative locations of the instrument and the luminosity.

\section{Observed Examples of Dayside Breakup Events}

\subsection{A Westward Moving Event on January 12, 1988}

This event has been presented and discussed by Sandholt et al. [1990b] and Lockwood et al. [1989b], and the reader is referred to these papers for a detailed description of the event and a full presentation of the data. In this section, we reanalyze the meridian-scanning photometer data, using the mapping curves shown in Figure 2, as will also be done for an event on January 9, 1989, in the following section. Images from the $630-\mathrm{nm}$ charged-couple device camera were not available for this day.

This event was revealed to be moving westward by the intensifier-silicon-intensifier target all-sky camera (mainly sensitive to $557.7-\mathrm{nm}$ light) and by the EISCAT radar flow measurements. This motion was consistent with the event being on newly opened field lines as the IMF $B_{y}$ component was measured to be strongly positive at this time. Note $B_{y}$ also showed very little variation, so the event does not simply represent the effects of an increase in IMF $B_{y}$ for a constant magnetopause reconnection rate.

Meridian-scanning photometer data. Figure 3 analyzes the northward motions of the peak intensity of various features observed by the meridian-scanning photometers during this event. The solid lines show the latitudes of the transient $557.7-\mathrm{nm}$ auroral forms as a function of time, mapped using the assumed emission altitude of $110 \mathrm{~km}$. All show a fluctuating poleward motion the speed of which initially averages $0.63 \mathrm{~km} \mathrm{~s}^{-1}$, which would give the straight dashed line. The dashed data curve shows a $630-\mathrm{nm}$ transient near zenith which has been mapped for an emission altitude of $250 \mathrm{~km}$. The dot-dashed curves are for the peak of the main 630-nm transient. This has been plotted for three assumed values of $h$. For the higher two ( 400 and $550 \mathrm{~km}$ ) the red-line emissions have a mean lifetime of $\tau=110 \mathrm{~s}$. Hence to allow comparison with the 557.7-nm emissions ( $\tau=$ $3 / 4 \mathrm{~s}$ ), the 630 -nm plots have been shifted along the time axis by this lifetime, such that the plots attempt to show the time at which the oxygen atoms were excited, rather than the time at which they emit the 630-nm photon. For any curve for which the assumed value of $h$ is $250 \mathrm{~km}$, the lifetime $\tau$ has been reduced to $55 \mathrm{~s}$. This is because quenching of $630-\mathrm{nm}$ emissions is important at this lower altitude. The excited

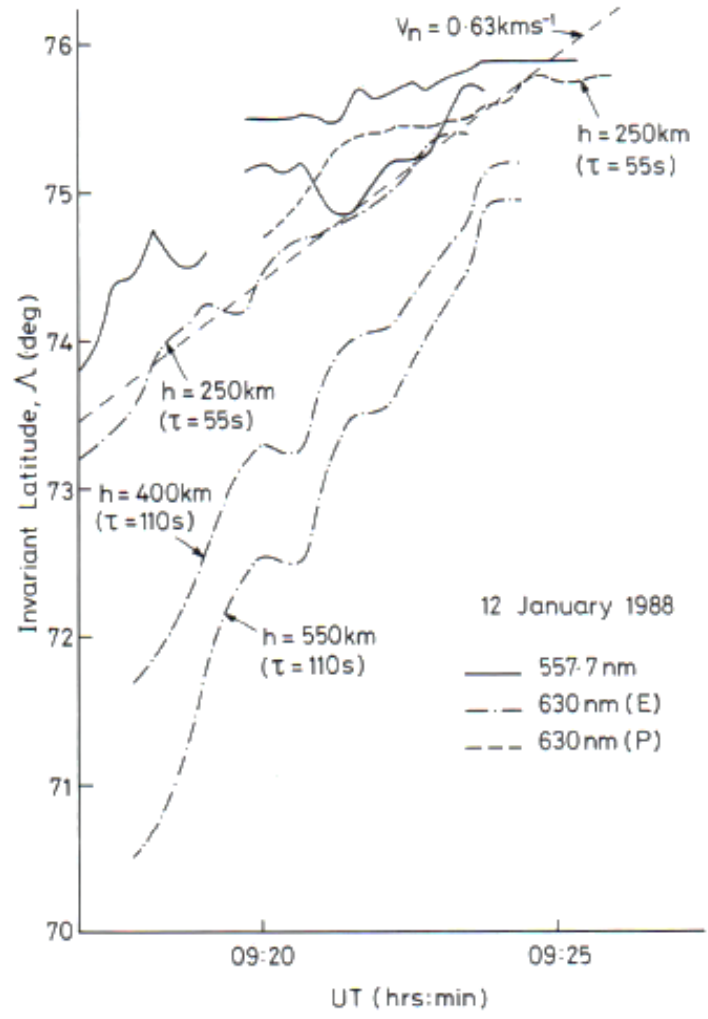

Fig. 3. The invariant latitude, $\Lambda$, as a function of UT of various features observed by the meridian scanning photometers during the second event on January 12, 1988 [see Lockwood et al, 1989b, Figure 2]. The solid lines are for the peak emission of $557.7 \mathrm{~nm}$, mapped assuming an emission altitude, $h$, of $110 \mathrm{~km}$. The dashed data curve is for the 630-nm transient observed near zenith, mapped for an assumed emission altitude of $250 \mathrm{~km}$. The dot-dashed curves are for the peak of the main 630-nm transient event, mapped for $h$ of $250 \mathrm{~km}, 400 \mathrm{~km}$ and $550 \mathrm{~km}$. In all cases, the $630-\mathrm{nm}$ forms have been mapped at the predicted time of excitation of the oxygen atoms, a time $\tau$ before the observation time. For $h$ of $550 \mathrm{~km}$ and 400 $\mathrm{km}, \tau$ is taken to be $110 \mathrm{~s}$, but for $h$ of $250 \mathrm{~km}, \tau$ is reduced to $55 \mathrm{~s}$ to allow for quenching. The straight dashed line shows the locations for features moving poleward at a constant speed of $0.63 \mathrm{~km} \mathrm{~s}^{-1}$.

states which deexcite by collisions will tend to be those which have the higher values of the distribution of lifetimes. Hence the states which do emit will tend to have shorter lifetimes and the mean $(\tau)$ will be lower. Hence a $\tau$ of $55 \mathrm{~s}$ has been used for an emission altitude of $250 \mathrm{~km}$, where collisions are much more prevalent.

Comparison of the deduced motion of the main $630-\mathrm{nm}$ transient, shown in Figure 3 for the three assumed emission altitudes, reveals that it would be moving north more rapidly than the $557.7 \mathrm{~nm}$ for the higher two of the altitudes presented. This is not the behavior predicted by Figure 1. On the other hand, the $250-\mathrm{km}$ altitude gives a poleward speed which matches that of the 557.7-nm transient well, which is consistent with Figure 1.

Figure 4 analyzes the relative locations of the transient aurorae during this event, by plotting the emission intensity I as a function of invariant latitude. The dashed curve shows the 557.7-nm emissions for the scan commencing at 0921:30 UT, whereas the other two curves are for 630-nm emissions. The solid curve was recorded at 0922:24 UT and hence can be compared with the dashed curve if the mean lifetime of the excited oxygen atom is $\tau=56 \mathrm{~s}$. This is roughly 
12 January 1988

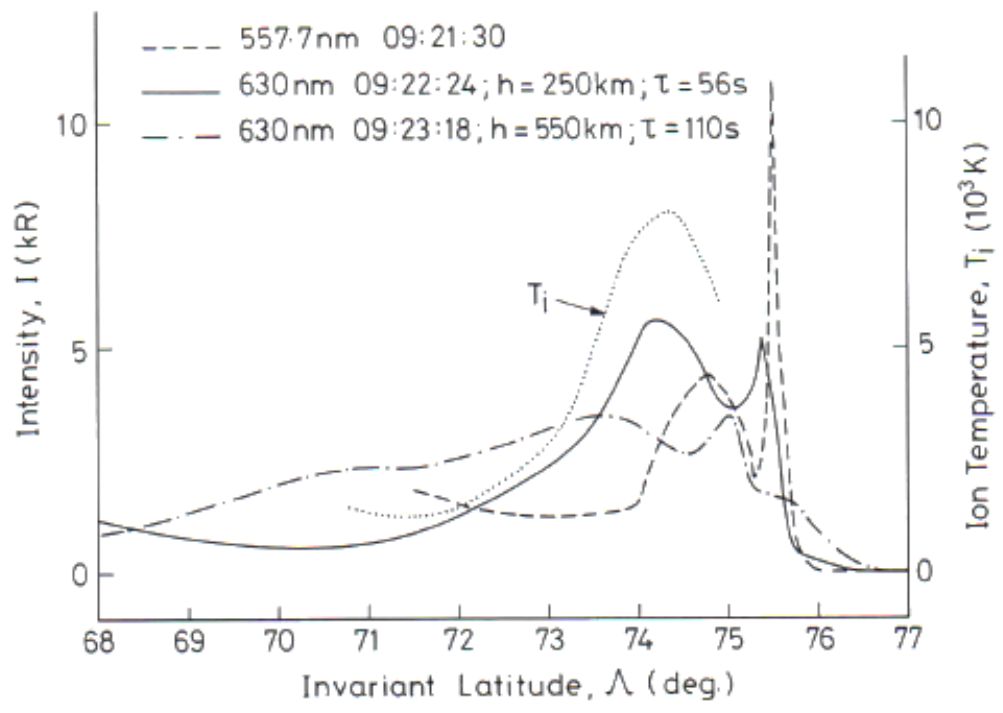

Fig. 4. The intensity $I$ of transient emissions over and to the south of $\mathrm{Ny}$ Ålesund as a function of invariant latitude $\Lambda$ for the event on January 12, 1988, addressed by Figure 3. The dashed line is the 557.7-nm emissions observed at 0921:30 UT and mapped assuming $h=110 \mathrm{~km}$. The solid line is the equivalent 630-nm emissions for an assumed emission altitude of $h=250 \mathrm{~km}$ (observed at the time 0922:24 UT, that is, for a deexcitation lifetime $\tau$ of $56 \mathrm{~s}$ ) and the dot-dashed line is that for $h=550 \mathrm{~km}$ (observed at 0923:18 UT, that is, for $\tau=110 \mathrm{~s}$ ). The dotted line shows the latitude profile of the ion temperature observed by azimuth 2 of the EISCAT Polar Experiment over the integration period 0922:20-0924:30.

consistent with an emission altitude of $250 \mathrm{~km}$, which is the value used to map the data onto the invariant latitude scale. The dot-dashed curve shows the data recorded in the scan commencing 0923:18 UT, which was mapped assuming an emission altitude of $550 \mathrm{~km}$ (which can be compared with the given green-line latitude profile if $\tau=110 \mathrm{~s}$.)

The dashed line shows a very strong peak on the poleward edge of the $630-\mathrm{nm}$ transient. This is true irrespective of the altitude from which the $630-\mathrm{nm}$ light is assumed to have originated. The solid line shows a secondary peak very close to this narrow $557.7-\mathrm{nm}$ feature, suggesting that this $630-\mathrm{nm}$ emission originated from a low altitude on the same field line. Equatorward, the latitudinal extent of the 630-nm event depends greatly upon the assumed emission altitude. For 250 $\mathrm{km}$ the event $(I>1 \mathrm{kR})$ extends to about $72^{\circ}$, whereas for $550 \mathrm{~km}$, it reaches $68.5^{\circ}$. It should be noted that in the poleward half of the mapped 630-nm emission (for either altitude) there is some $557.7-\mathrm{nm}$ emission, of peak intensity about one third of that for the narrow feature on the poleward edge. Figure 4 illustrates how sensitive the derived extent of the $630-\mathrm{nm}$ transient is to the assumed emission altitude.

EISCAT radar data. For both of the events discussed in this paper, the EISCAT radar was operating in the Polar Experiment mode. This beam-swinging mode employs a beam elevation of $21.5^{\circ}$ and two azimuths of $332^{\circ}$ and $356^{\circ}$ (east of geographic north at Troms $\emptyset, T$ ), termed azimuths 1 and 2. These beam directions are plotted on the map shown in Figure 5. It can be seen that azimuth 2 passes close to the east of the Ny Ålesund and is at a reasonably small angle to the photometer direction. The radar employs a 5-min cycle, dwelling $130 \mathrm{~s}$ at each azimuth and taking $20 \mathrm{~s}$ to swing between them. Hence the entire cycle lasts $5 \mathrm{~min}$.

The dotted line in Figure 4 shows the ion temperature as a function of invariant latitude, as observed along the azimuth 2 , for the dwell that is closest in time to the photometer scans

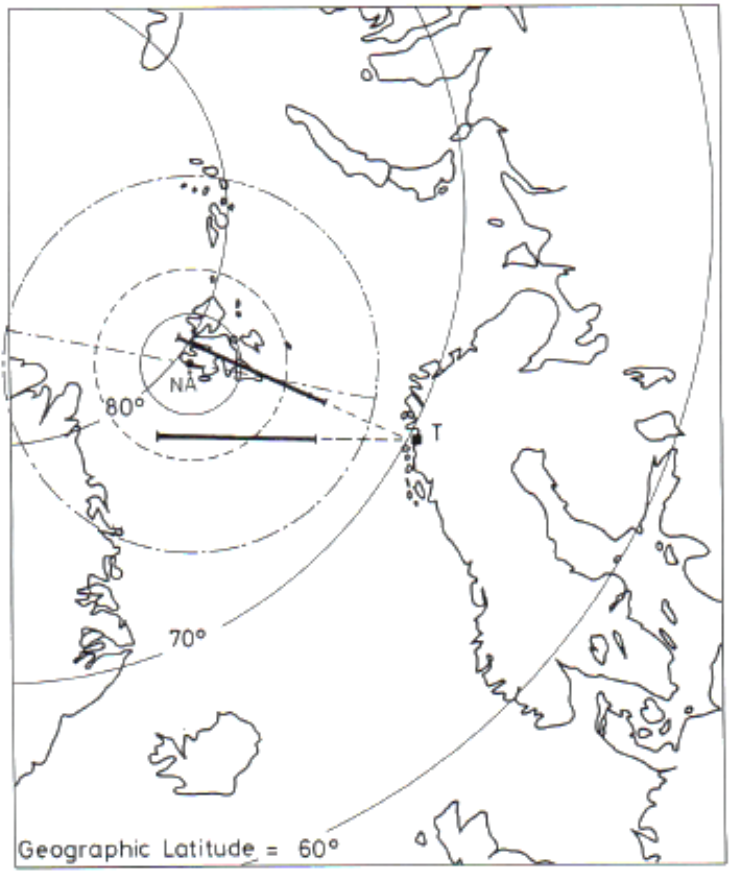

Fig. 5. Map showing the two beam directions of the EISCAT Polar Experiment, relative to the fields of view of the optical instruments at Ny Älesund, Svalbard (NÅ). The data used in this paper were recorded at Troms $\varnothing(\mathrm{T})$ and are for the beam segments shown as thick solid lines. The circles show the zenith angle contours for $\chi=60^{\circ}$ (that is, the second concentric circle in Plate 1). The solid circle is for the ISIT camera which is largely sensitive to $557.7-\mathrm{nm}$ light, which is assumed to originate from an altitude $h$ of $110 \mathrm{~km}$. The dashed and dot-dashed circles are for the CCD camera, sensitive to only 630-nm light, for $h$ of 250 and $500 \mathrm{~km}$, respectively. The straight dot-dashed line is the meridian scanned by the photometers. 
TABLE 1. Inferred Plasma Velocities for 0922:20-0924:30 UT on January 12, 1988

\begin{tabular}{ccccccc}
\hline $\begin{array}{c}\text { Gate } \\
\text { Number }\end{array}$ & $\begin{array}{c}\text { Invariant } \\
\text { Latitude, } \\
\text { deg }\end{array}$ & $\begin{array}{c}T_{i}, \\
\mathrm{~K}\end{array}$ & $V_{\text {los }}$ & $\begin{array}{c}V_{i}, \\
\mathrm{~km} \mathrm{~s}^{-1}\end{array}$ & $V_{n}$ & $V_{w}$ \\
\hline 3 & 72.0 & 1403 & 0.20 & 0.88 & 0.37 & 0.80 \\
4 & 72.6 & 2108 & 0.36 & 1.37 & 0.63 & 1.22 \\
5 & 73.2 & 3400 & 0.20 & 2.00 & 0.61 & 1.91 \\
6 & 73.8 & 6149 & 0.24 & 2.85 & 0.63 & 2.78 \\
7 & 74.3 & 8000 & 0.17 & 3.30 & 0.85 & 3.19 \\
8 & 74.9 & 6000 & -0.09 & 2.80 & 0.57 & 2.74 \\
\hline
\end{tabular}

shown. The spectra have here been analyzed with allowance for the non-Maxwellian nature of the ion velocity distribution. This can greatly influence the ion temperature derived when the ion drift is large, particularly for the low beam elevation employed here [Lockwood and Winser, 1988]. This analysis was carried out using the procedure described by Suvanto et al. [1989]. The large drifts in the events mean that distortions of the ion distribution function were observed at this time [see Lockwood et al., 1989c].

The ion temperature variation shows a clear peak of near $7500 \mathrm{~K}$ at around $74.5^{\circ}$ and is at much lower values, close to the estimated thermospheric temperature of $900 \mathrm{~K}$ [Lockwood et al., 1989c ], at $71.5^{\circ}$. The increase in ion temperature is at latitudes above $72^{\circ}$. For the pulsating cusp model the cusp particles precipitating down newly opened field lines produce 630 -nm emissions, while the ion temperature is simultaneously raised by the large drifts (due to the magnetic tension experienced by the field lines if the IMF $B_{y}$ component is large, as in this example). Hence for this case, the similarity of the latitude profiles of the ion temperature and the 630 -nm intensity for $h=250 \mathrm{~km}$ also suggests that this is the true emission altitude.

Table 1 presents an analysis of the plasma velocities in this event. This analysis is not based on the beam-swinging technique, but rather on the ion temperature and the line-ofsight velocity $\left(V_{\text {los }}\right)$ observed at azimuth 2 , close to the photometer meridian. The ion temperatures derived for the western azimuth (1) are very similar to those for this eastern one (2) throughout this event. Hence the beam-swinging assumption that the flow is uniform between the azimuths may remain reliable in this case (this is certainly not true for the other event described in the next section). However, here we will simply use the beam-swinging data to infer that the flow along the $L$ shells was westward and fast enough for the neutral wind speed and the electron-ion term (and all higher-order terms) in the ion heating equation to be neglected. Under such conditions, we can estimate the magnitude of the ion velocity $V_{i}$ from the simplified ion energy balance equation, as given by Lockwood et al. [1990c, equation (1)]. Given that the component of the flow normal to the radar beam is westward, this can be combined with $V_{\text {los }}$ to derive the northward and westward components of the plasma velocity $V_{n}$ and $V_{w}$, respectively. Table 1 shows that the northward flow derived this way is, for all gates, close to the value of about $0.6 \mathrm{~km} \mathrm{~s}^{-1}$ inferred for the optical transients (both the 557.7-nm transient and the main 630-nm transient for emission from $250 \mathrm{~km}$; see Figure 3). The peak westward flow speed of $3 \mathrm{~km} \mathrm{~s}^{-1}$ is very similar to the westward motion of the $557.7-\mathrm{nm}$ transient, as derived from the ISIT all-sky camera at this time [Sandholt et al., 1990a].
Hence the transient auroras are moving with the plasma flow, which is consistent with the flux transfer event model.

\subsection{An Eastward Moving Event on January 9, 1989}

In this section, we consider a second transient event observed at almost the same MLT as that reported in the previous section (in fact just 20 min earlier) on January 9 , 1989. This event has been presented and discussed by Lockwood et al. [1990c], and the reader is referred to that paper for presentations of the photometer data and $557.7-\mathrm{nm}$ images. However, Lockwood et al. [1990c] did not include the sequence of $630-\mathrm{nm}$ images, as observed by the CCD camera, which is discussed here. The main difference between this event and the previous one is that the images show it to be moving eastward. Simultaneous IMF data are not available for this event; however, similar eastward moving events on other days have been shown to be for $B_{y}$ $<0$ [Sandholt et al., 1992a, b].

630- $\mathrm{nm}$ all-sky camera data. The relative intensity detected by the CCD all-sky camera at Ny Alesund, with a $630-\mathrm{nm}$ filter, is shown in the all-sky images of Plate 1. These are 1-s integrated images, $2.5 \mathrm{~min}$ apart. The second concentric circle is the zenith angle contour for $60^{\circ}$, the location of which for assumed emission altitudes is given in Figure 5. The sequence starts with a dayside transient event commencing at 0834:00 UT near the western horizon and moving rapidly eastward. This event fills most of the poleward half of the imager field-of-view at 0844:00 UT, and the trailing edge propagates eastward during the period $0846: 30-0854$ : 00 . One should note that the sensitivity of the camera falls rapidly with zenith angle between $60^{\circ}$ and $90^{\circ}$, and hence at the peak of the event the camera does not define its full east-west extent.

The onset of the second event is not observed because of the data gap at 0901:30 UT, but it fills the northern half of the field of view at 0904:00 (20 min after the previous event was at a similar phase of its evolution). The trailing edge of the second event then moves eastward in the same manner as the first event. A smaller third event is underway by the end of the sequence at 0929:00 UT. If we compare the images at 0854:00 UT and 0914:00 UT, we find that the first and second events are then at a similar phase of their evolution near the eastern limb of the field-of-view, confirming the cycle time of about $20 \mathrm{~min}$ for these events. It is interesting to compare this sequence with that presented by Sandholt et al. [1992a] which revealed less extensive events, however, with a lower repetition period of about $8 \mathrm{~min}$.

This sequence could be interpreted as showing a relatively stable red-line arc to the south of Ny Allesund, with transient forms coming and going to the north of the site. However, we note that the background arc brightens and fades considerably at times, particularly to the west and hence is in reality far from steady and stable.

Table 2 considers the eastward motion of the 630-nm transient event on January 9, 1989, as derived by comparing successive images of the sequence. The clearest propagating feature is the trailing edge of the event, and the position of this is determined along the invariant latitude of $76^{\circ}$ for each image in which it is defined. The derived velocity of the event is initially $1.1 \mathrm{~km} \mathrm{~s}^{-1}$ for an assumed emission altitude of $h=250 \mathrm{~km}$. This value rises to $2.5 \mathrm{~km} \mathrm{~s}^{-1}$ for $h=550$ $\mathrm{km}$. These speeds are averages which apply to the period 0904:30-0909:00 UT. 


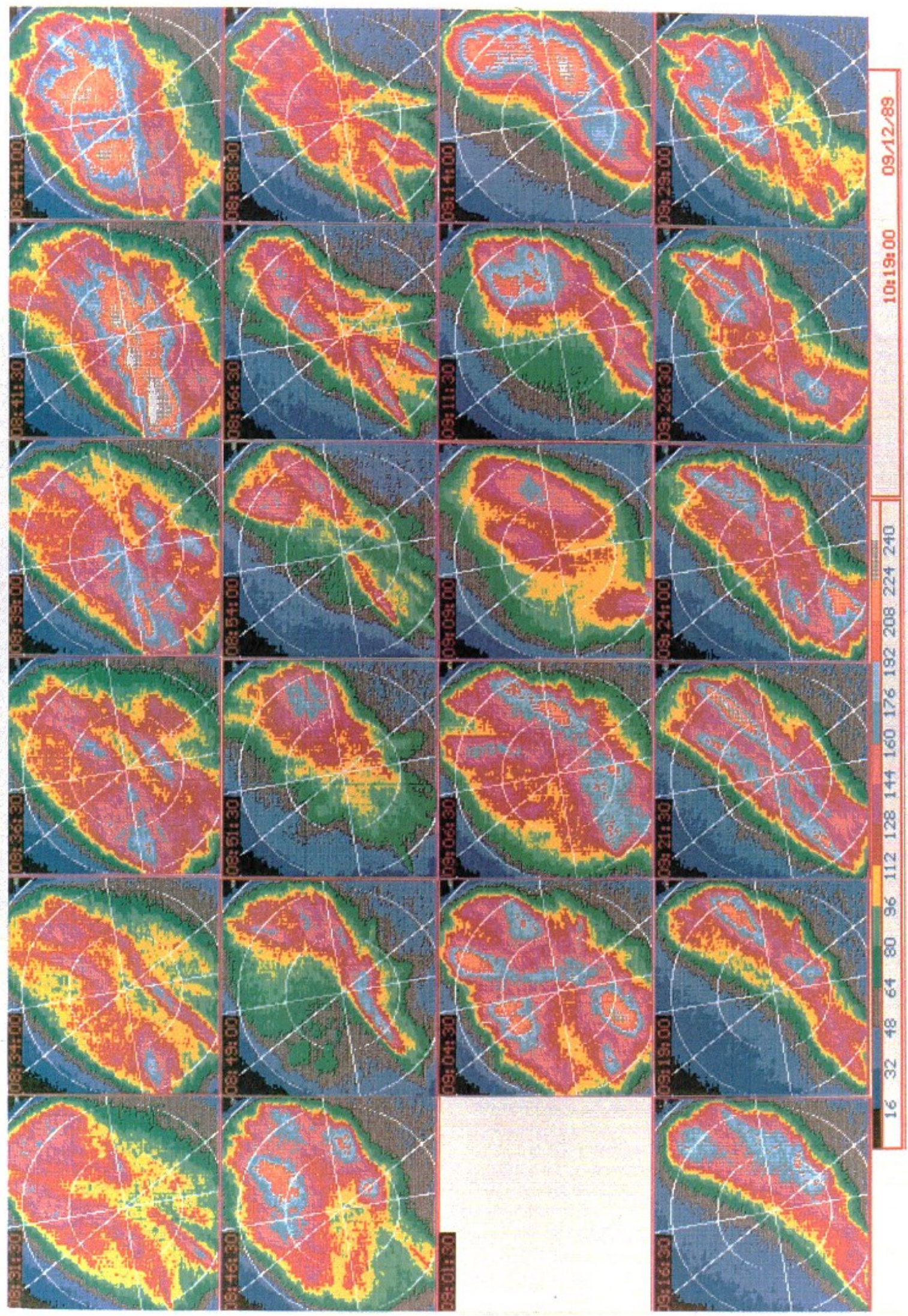


TABLE 2. Eastward Motion of Trailing Edge of 630-nm Transient on January 9,1989

\begin{tabular}{ccccc}
\hline UT & $\chi$, deg & $h=250 \mathrm{~km}$ & $\begin{array}{c}V_{e}, \mathrm{~km} \mathrm{~s}^{-1} \\
h=400 \mathrm{~km}\end{array}$ & $h=550 \mathrm{~km}$ \\
\hline $0904: 30$ & $57 \mathrm{~W}$ & 1.125 & 1.800 & 2.475 \\
$0905: 30$ & & 1.125 & 1.800 & 2.475 \\
$0906: 30$ & $45 \mathrm{~W}$ & 0.988 & 1.581 & 2.174 \\
$0907: 45$ & & & & \\
$0909: 00$ & $18 \mathrm{~W}$ & & 0.640 & 0.887 \\
$0910: 15$ & & & & \\
$0911: 30$ & $15 \mathrm{E}$ & 0.403 & & \\
$0912: 45$ & & &
\end{tabular}

Meridian-scanning photometer data. Figure 6 analyzes the northward motions of the peak intensity of various features observed by the meridian-scanning photometers, during the second of the events shown by the sequence in Plate 1. As in Figure 3, the solid lines show the latitudes of the transient $557.7-\mathrm{nm}$ auroral forms as a function of time, mapped using the assumed emission altitude of $110 \mathrm{~km}$. All show a relatively steady poleward motion at about the same speed as the event studied in the previous section. For comparison purposes, the straight dashed lines give the same poleward speed of $0.63 \mathrm{~km} \mathrm{~s}^{-1}$ as in Figure 3. Hence the two events studied in this paper are very different in their east-west motion but move poleward at a similar speed which is around $0.6 \mathrm{~km} \mathrm{~s}^{-1}$. The dashed data curve shows a $630-\mathrm{nm}$ transient near zenith which has been mapped for an emission altitude of $250 \mathrm{~km}$, because it appears to be colocated with the $557.7-\mathrm{nm}$ transients.

The dot-dashed curves are for the peak of the main 630-nm transient. This has been plotted for the same three assumed values of $h$ as used in Figure 3 for the westward moving event. The same relationship between the lifetime of the excited state and the emission altitude has been applied. Figure 6 shows that the poleward motion of the $630-\mathrm{nm}$ transient matches that of the other transient aurora if the emission altitude is higher rather than lower, given that the average poleward motion appears to be too slow for the lowest of the altitudes shown $(250 \mathrm{~km})$. However, we cannot state the altitude with certainty because the errors in this comparison are great.

Figure 7 analyzes the relative locations and intensities of the transient aurorae by plotting the emission intensity as a function of latitude for the northern part of the scan. (In the southern part of the scan a second $630-\mathrm{nm}$ peak is observed, which from the stacked photometer plots [see Lockwood et al., 1990c] can be interpreted as either a continuation of a steady background or the next in the series of poleward events forming). As in the corresponding plot for the westward moving event on January 12, 1988 (Figure 4), the dashed curve shows the 557.7-nm emissions (for the scan commencing at 0902:49 UT), whereas the other two curves are for $630-\mathrm{nm}$ emissions. The solid curve was recorded at 0903:43 UT, and hence can be compared with the dashed curve if the mean lifetime of the excited oxygen atom is $\tau=$

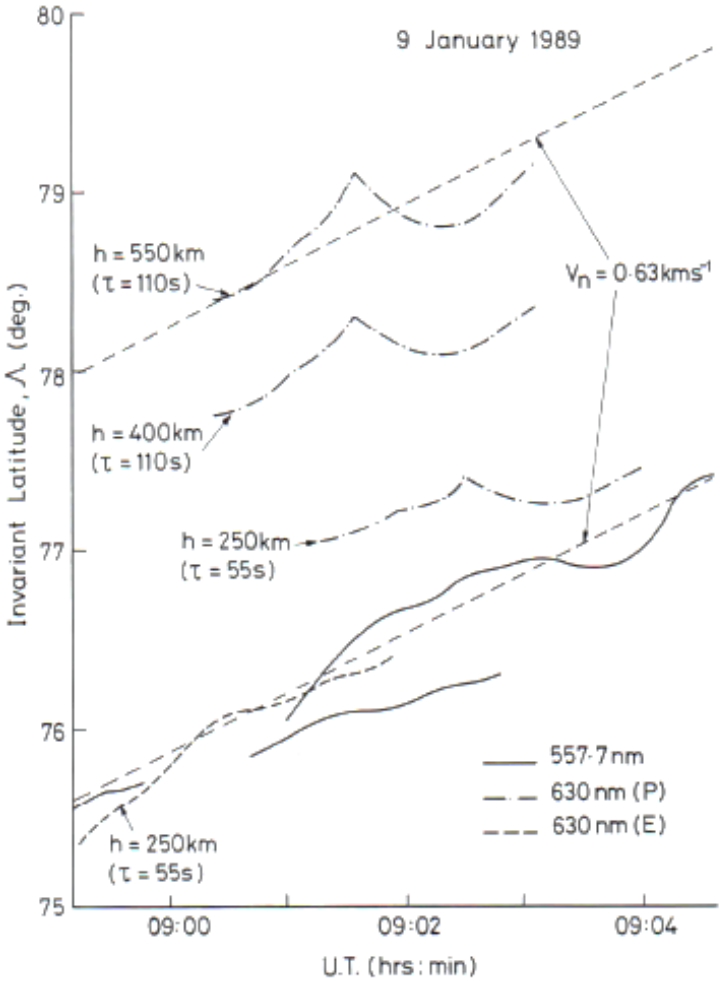

Fig. 6. The invariant latitude $\Lambda$ of various features observed ny the meridian-scanning photometers during the event on January 9 , 1988, shown in Plate 1. The plot format is the same as for Figure 3. The straight dashed lines show the locations for features moving poleward at a constant speed of $0.63 \mathrm{~km} \mathrm{~s}^{-1}$ (the same as Figure 3 to allow comparisons)

$56 \mathrm{~s}$. This is roughly consistent with an emission altitude of $250 \mathrm{~km}$, which is the value then used to map the data onto the invariant latitude scale. The dot-dashed curve shows the data recorded in the scan commencing 0904:39 UT mapped assuming an emission altitude of $550 \mathrm{~km}$. (This can be compared with the shown green-line latitude profile if $\tau=$ $110 \mathrm{~s}$.

For either of the assumed emission altitudes we find that the 557.7-nm transient lies on the equatorward edge of the eastward moving transient 630 -nm form. Hence this is consistent with Figure $1 b$, in which case we would interpret the $630-\mathrm{nm}$ peak to the south of zenith as the cleft and the transient form poleward of the $557.7-\mathrm{nm}$ arc as the cusp. It should be noted that the 557.7-nm arc is here shown as being about $0.5^{\circ}$ wide (equivalent to about $60 \mathrm{~km}$ ). This may be an overestimate of the true width because, for the large zenith angle at which it was detected, the apparent width will have been increased by any spread in altitudes from which the $557.7-\mathrm{nm}$ light is emitted. On the other hand, the red-line transient is 3 times wider for $h=250 \mathrm{~km}$ and is $6-7$ times larger for $h=550 \mathrm{~km}$.

Plate 1. (Opposite) A sequence of 1-s all sky camera images recorded from Ny-Ålesund on January 9, 1989 using the 630-nm emission line. The images shown are $2.5 \mathrm{~min}$ apart. Each plot shows the zenith angles $\chi$ of $30^{\circ}$ and $60^{\circ}$ as complete concentric circles and the $90^{\circ}$ circle can be seen in the top right (northeast) corner of each frame. The perpendicular crossed lines are the geographic north-south and east-west directions and the single diagonal line is the magnetic meridian scanned by the photometers (see also Figure 5). 
Experiment : SP-UK-POLH Both Azimuths

Time Interval : 08:15:00 9 January 1989 - 09:45:00 9 January 1989

a

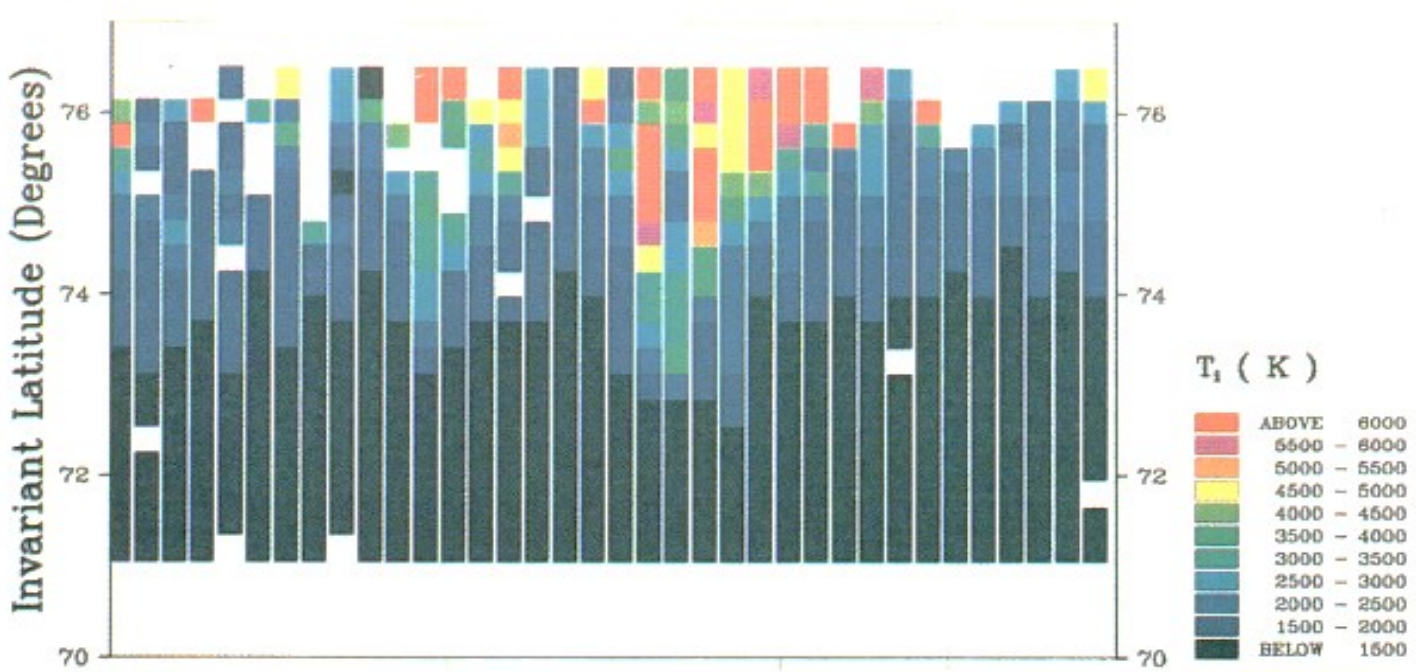

b

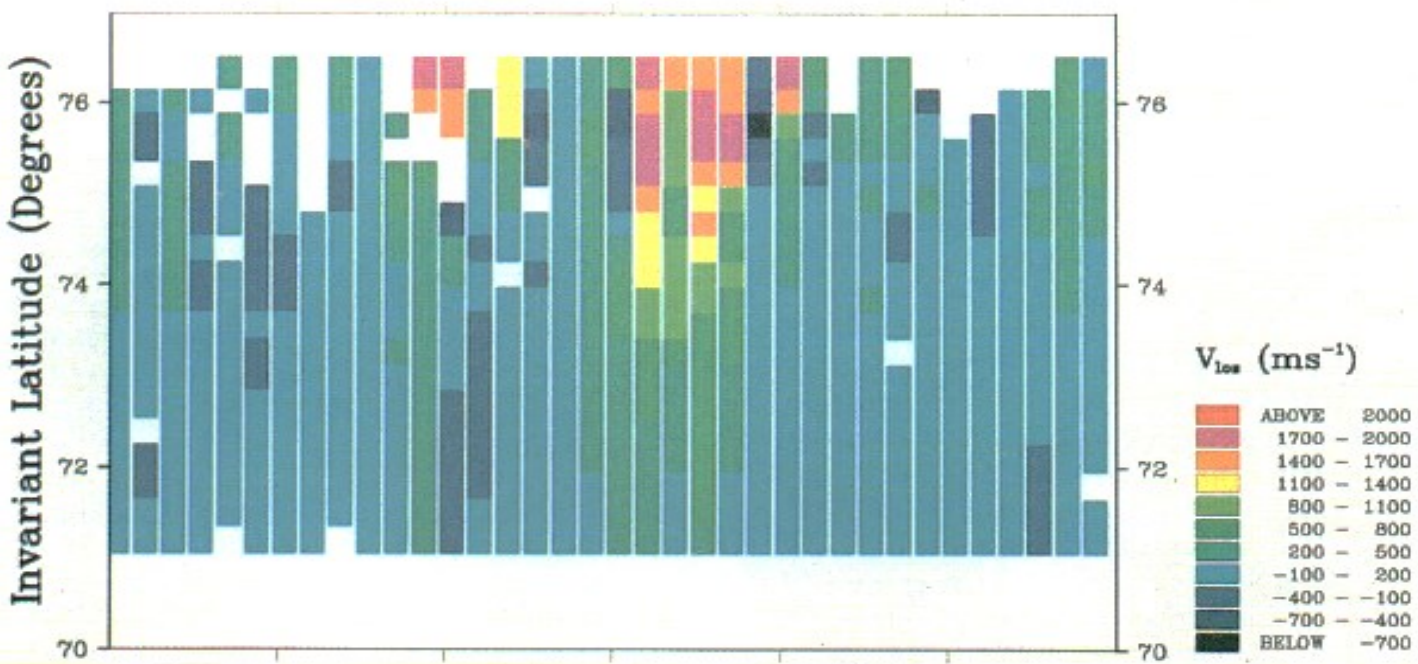

C

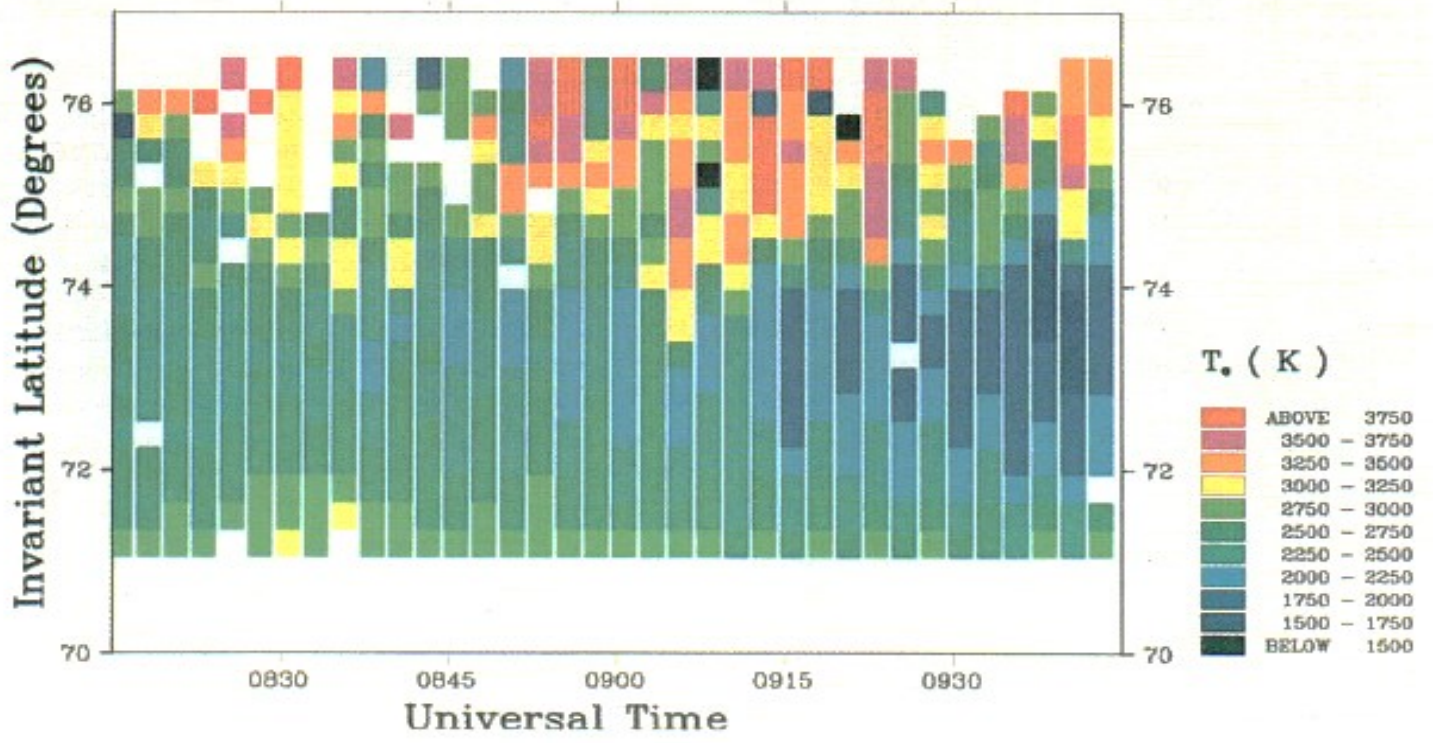




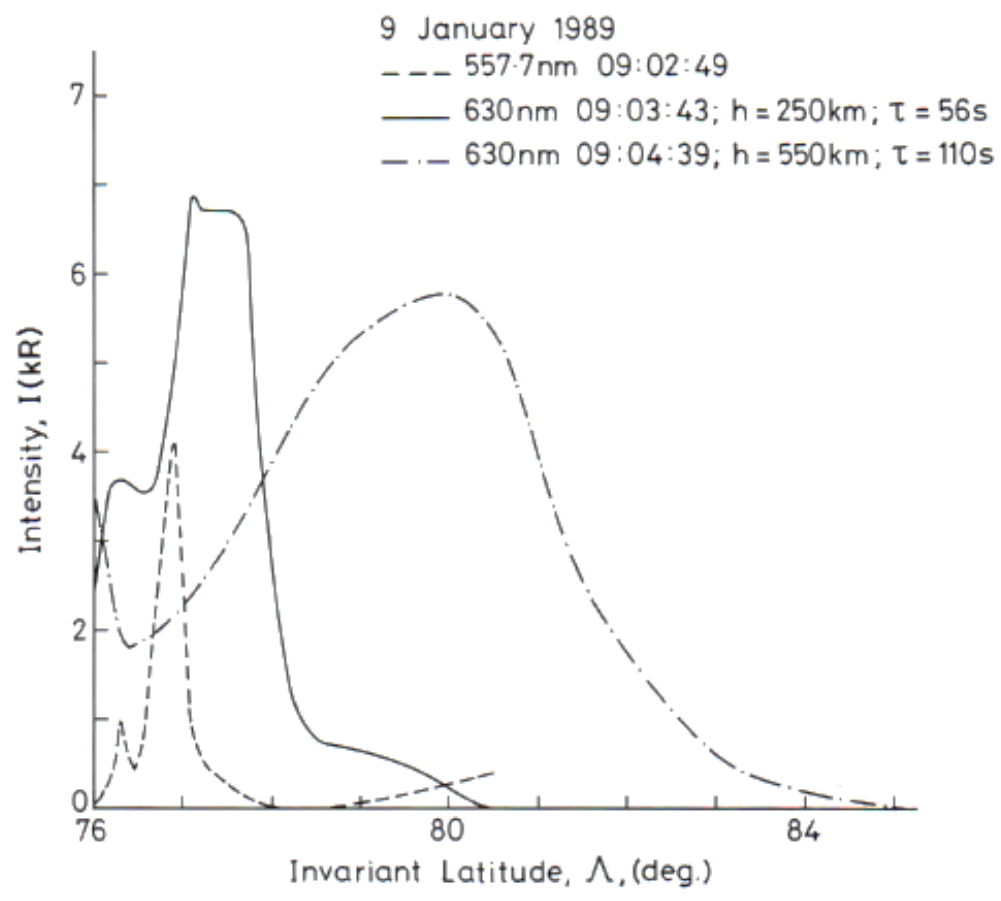

Fig. 7. The intensity $I$ of transient emissions to the north of $\mathrm{Ny}$ Ålesund as a function of invariant latitude $\Lambda$ for the second event on January 9, 1989, shown in Figure 6. The dashed line indicates the 557.7-nm emissions observed at 0902:49 UT and is mapped assuming $h=110 \mathrm{~km}$. The solid line is the equivalent $630-\mathrm{nm}$ emissions for an assumed emission altitude of $h=250 \mathrm{~km}$ (observed at the time 0903:43 UT, that is, for a deexcitation lifetime $\tau$ of $56 \mathrm{~s}$ ), and the dot-dashed lines are for the peak of the main 630-nm transient for $h=250,400$, and $550 \mathrm{~km}$ (the latter two were observed at 0904:39 UT, that is, for $\tau=110 \mathrm{~s}$ ).

EISCAT radar data. Evidence supporting the idea that the transient $630-\mathrm{nm}$ emissions may arise from the greater altitudes comes from comparing the EISCAT radar data with the images shown in Figure 5. Plate $2 a$ shows the ion temperatures observed during these events, whereas Plate $2 b$ shows the line-of-sight velocities and Plate $2 c$ shows the observed electron temperatures. The plot shows data from both of the two azimuths of the radar experiment, which are addressed in turn in the 5-min beam-swinging cycle. Periods when the antenna is in motion show up as white strips. The first latitude profile shown is for the easterly azimuth 2 , as is every other profile thereafter. These alternate with the data from the other, westerly azimuth (1). The first event seen by the optical instruments corresponds to the rise in ion temperatures around $0845 \mathrm{UT}$, the equatorward edge of which then propagates poleward out of the radar field of view. The second event causes a more major event between about 0902:30 and 0925:00 UT. The radar beam direction close to the center of the Ny Ålesund camera field of view (azimuth 2) observes greatly elevated ion temperatures commencing at 0902:30 UT, which move poleward at both azimuths and at an average of $0.65 \mathrm{kms}^{-1}$. This ion heating is within the radar field of view until after 0915:00 UT. Because the transient feature is further from the radar than the January 12,1988 , case, these high ion temperatures are observed at a much greater altitude (over $550 \mathrm{~km}$ ), for which ion-ion collisions are expected to destroy the non-Maxwellian distortions and anisotropy of the ion velocity distribution [Tereschenko et al., 1991], as were observed at lower altitudes in the event on January 12,1988. Indeed, analysis of the radar spectra using the non-Maxwellian procedure reveals no non-Maxwellian distortion, despite the exceedingly high ion temperatures and large aspect angle of the observations. Hence we assume that the derived line-ofsight ion temperature is the three-dimensional ion temperature which is used in the ion energy balance equation [Lockwood and Winser, 1988].

The high ion temperatures observed at azimuth 1 in the period 0902:30-0907:30 UT are over $6000 \mathrm{~K}$, compared with an estimated neutral temperature of $1250 \mathrm{~K}$. From the ion energy balance equation, this requires an ion drift of about $2.7 \mathrm{~km} \mathrm{~s}^{-1}$ at this azimuth [see Lockwood et al., 1990c]. Such greatly elevated ion temperatures are not observed in the azimuth 2 at these times, and hence the beam-swinging technique cannot give reliable vectors because the flow is so spatially structured within the EISCAT field-of-view: the technique is therefore not used here. Table 3 presents an analysis of the flow at azimuth 2 using the same procedure as applied to the January 12, 1988 event in Table 1. From the ion temperatures when the ion drift is low, the thermo-

Plate 2. (Opposite) EISCAT radar data on January 9, 1989: (a) the ion temperatures, $T_{i}$ and $(b)$ the line-of-sight velocities $v_{\text {los }}$ and $(c)$ the electron temperature $T_{e}$. Data are shown for both azimuths used by the SP-UK-POLH experiment ( $332^{\circ}$ and $356^{\circ}$ east of geographic north from Troms $\varnothing$ ) which are viewed alternately in a 5-min beam-swinging cycle. The white strips mark the times when the antenna is in motion. 
TABLE 3. Inferred Plasma Velocities for 0905:30—0907:40 UT on January 9, 1989

\begin{tabular}{ccccccc}
\hline $\begin{array}{c}\text { Gate } \\
\text { Number }\end{array}$ & $\begin{array}{c}\text { Invariant } \\
\text { Latitude, } \\
\text { deg }\end{array}$ & $\begin{array}{c}T_{i}, \\
\mathrm{~K}\end{array}$ & $\begin{array}{c}V_{\text {los }} \\
\mathrm{km}\end{array}$ & $\begin{array}{c}V_{i}, \\
\mathrm{~km}\end{array}$ & $\begin{array}{c}V_{n}, \\
\mathrm{~km}\end{array}$ & $\begin{array}{c}V_{w}, \\
\mathrm{~km}\end{array}$ \\
\hline 15 & 75.38 & 2301 & 0.84 & 1.28 & 0.62 & -1.12 \\
16 & 75.64 & 2725 & 0.88 & 1.50 & 0.60 & -1.37 \\
17 & 75.90 & 3807 & 0.95 & 1.99 & 0.57 & -1.91 \\
18 & 76.16 & 4127 & 0.98 & 2.11 & 0.57 & -2.03 \\
\hline
\end{tabular}

spheric temperature employed is $1250 \mathrm{~K}$. Table 3 only shows those latitudes for which the ion temperature and the signalto-noise ratio are both sufficient to allow this calculation to be made. Comparison with Figure 7 indicates that the radar observed the eastward flow speed increasing as the latitude increased toward the location of the $557.7-\mathrm{nm}$ transient. Table 3 shows the northward plasma velocity is always close to the $0.6 \mathrm{~km} \mathrm{~s}^{-1}$ calculated from the transient auroras in Figure 6. The eastward flow speed on the equatorward edge of the event is of the order of $2.0 \mathrm{~km} \mathrm{~s}^{-1}$ and is probably greater than this at the latitude of the peak of the 630 -nm transient $\left(77.5^{\circ}\right.$ and $80.0^{\circ}$ for emission altitude of 250 and 550 $\mathrm{km}$, respectively, both beyond the radar field of view).

Hence we find that the northward motion of the main $630-\mathrm{nm}$ transient is consistent with that of the $557.7-\mathrm{nm}$ transients and the same as the poleward plasma flow deduced from EISCAT, if the peak $630-\mathrm{nm}$ emission is at an altitude of $550 \mathrm{~km}$. Furthermore, comparison of Tables 2 and 3 shows that the eastward event motion and the eastward plasma flow are the same if the emission altitude is somewhat greater than $500 \mathrm{~km}$. For the transient reconnection model of these events, the optical features should move with the same flow speed as the plasma within them. This has been found to be true for the strong $557.7-\mathrm{nm}$ arcs observed moving westward. However, it is only true for the $630-\mathrm{nm}$ arcs observed here moving eastward if the emission comes from an altitude of at least $500 \mathrm{~km}$, and $550 \mathrm{~km}$ is the best estimate. Given the uncertainties in this comparison, we regard $400-500 \mathrm{~km}$, as the most likely range of values for the peak emission altitude, but we note that this may be a somewhat conservative estimate as the height is more likely to be above $500 \mathrm{~km}$ than it is to be below $400 \mathrm{~km}$. An altitude of $500 \mathrm{~km}$ would give an event (and hence plasma) speed of $2.4 \mathrm{~km} \mathrm{~s}^{-1}$ and an ion temperature within the event of at least $5000 \mathrm{~K}$. Plate $2 a$ shows such temperatures were frequently observed in this event.

For the time period of concern in Figure 6 (January 9, 1989, 0900-0904 UT), measurement of $T_{e}$ by the radar, near $78^{\circ}$ invariant latitude, involves error bars too large to serve as a direct test for thermal excitation of $630-\mathrm{nm}$ emission around $400-500 \mathrm{~km}$. At this latitude, even if the error bars were small, interpretation would be complicated by the need for extrapolation of $T_{e}$ from the measurement altitude of about $680 \mathrm{~km}$ down the magnetic field line to $400-500 \mathrm{~km}$. However, good quality data were obtained up to $76.9^{\circ}$ invariant latitude at 0855:30-0857:30 UT. Examination of those data shows a latitude at and above which $T_{e}$ was sufficiently high to meet the criteria discussed in section 2 for high-altitude thermal excitation of the $O\left({ }^{1} \mathrm{D}\right)$ state and hence 630-nm emission. The maximum $T_{e}$ observed exceeded 4000 $\mathrm{K}$, at $76.3^{\circ} \Lambda$ and at $550 \mathrm{~km}$ altitude. Strongly enhanced plasma drift velocity, as evidenced by $T_{i}$ and line-of-sight velocity enhancements, was measured 1-2 range gates further north $\left(76.6^{\circ}-76.9^{\circ} \Lambda\right)$. Extrapolating the $T_{e}$ peak northward at the inferred drift velocity of $0.6 \mathrm{kms}^{-1}$, tracks the 630-nm enhancement on Figure 6 at an altitude of about $400-500 \mathrm{~km}$. While certainly not proof, this consistency between the location of the extrapolated $T_{e}$ peak and that estimated for the observed $630-\mathrm{nm}$ enhancement, again reinforces the case for a high source altitude of this $630-\mathrm{nm}$ emission. It is interesting to note that for the other event discussed in this paper (January 12, 1988, around 0920), the observed $T_{e}$ was well below the threshold for any significant thermal excitation of $630 \mathrm{~nm}$. Hence the above considerations are again consistent with the altitude of the $630-\mathrm{nm}$ enhancement estimated from the motions of the transients; however, in the January 12, 1988, case that altitude is near $250 \mathrm{~km}$, whereas in the January 9,1989 , case it is probably in the range $400-500 \mathrm{~km}$. The emission altitudes inferred for January 9, 1989, are slightly, but not greatly, greater than the value of $400 \mathrm{~km}$ derived from Sondrestromfjord data by Wickwar and Kofman [1984] for slightly more intense emissions.

\section{ImPLiCATIONS OF THE High-EMisSion Altitude}

As discussed in the introduction, estimates of the reconnection voltage in, and of the contribution to the averaged transpolar voltage of, these events vary as the square of the assumed emission altitude.

On January 12, 1988, the emission altitude appears to be relatively low, that is, around $250 \mathrm{~km}$. This yields a northsouth extent of the $630-\mathrm{nm}$ transient of about $300 \mathrm{~km}$. This is the same as derived from the radar flow measurements by Lockwood et al. [1990 b]. The 630-nm transient persists for over $400 \mathrm{~s}$, and the radar data show that the peak westward flow at the center of the transient $630-\mathrm{nm}$ region of $3.2 \mathrm{~km}$ $\mathrm{s}^{-1}$ (see Table 1) is maintained for this period. This yields an east-west dimension for this event of $1300 \mathrm{~km}$ and, for a simplistic elliptical shape, an area of $A=3 \times 10^{11} \mathrm{~m}^{2}$ and a flux of $\Delta F=(A) B_{i}=1.5 \times 10^{7} \mathrm{~Wb}$. Note that an ellipse is used here only to give a crude estimate of the area: Figure 1 illustrates that the true shape of the event will evolve during the events lifetime. For the reconnection time $\Delta t=2$ min discussed in the introduction, the reconnection voltage $(\Delta F / \Delta t)$ is $125 \mathrm{kV}$. This event follows another at an interval $\Delta \tau$ of about $10 \mathrm{~min}$; hence the contribution to convection is $(\Delta F / \Delta \tau)=25 \mathrm{kV}$.

Images of 630-nm emission, like those shown in Plate 1, would give a much more satisfactory way to determine both dimensions of the 630-nm events, if the emission altitude were known. Here we shall consider the voltages for the January 9, 1989, event using small and large values for $h$ of 250 and $500 \mathrm{~km}$. Given that the analysis presented in section 3.2 indicates that the main $630-\mathrm{nm}$ peak arises from closer to the greater of these two values than the smaller, we infer that the larger values will be the more applicable to this event.

From Figure 7, the 630-nm transient, observed poleward of the $557.7-\mathrm{nm}$ feature at 0904:39 UT has a north-south extent of $640 \mathrm{~km}$ for $h=500 \mathrm{~km}$ and $320 \mathrm{~km}$ for $h=250 \mathrm{~km}$. At this time (0904:30 UT) the event can be seen in Plate 1 to extend along the Ny Ålesund $L$ shell from a zenith angle of about $\theta_{1}=60^{\circ}$ to the west and at least $\theta_{2}=75^{\circ}$ to the east. This is a minimum estimate as the camera has very little 
sensitivity for zenith angles greater than this. The east-west extent is $h\left(\tan \theta_{1}+\tan \theta_{1}\right)$, which is therefore a huge 2750 $\mathrm{km}$ for $h=500 \mathrm{~km}$, but only $1375 \mathrm{~km}$ for $h=250 \mathrm{~km}$. Again, using an elliptical shape for simplicity, we derive areas of $1.4 \times 10^{12} \mathrm{~m}^{2}$ and $3.4 \times 10^{11} \mathrm{~m}^{2}$ and corresponding magnetic fluxes of $6.8 \times 10^{7} \mathrm{~Wb}$ and $1.7 \times 10^{7} \mathrm{~Wb}$, respectively. From the images we observe this patch to chiefly grow in the interval 0858:30-0904:30 (that is, $\Delta t=6$ min), which yields a reconnection voltages $(\Delta F / \Delta t)=188$ and $47 \mathrm{kV}$. In addition, the period between events is here $\Delta \tau$ $=20 \mathrm{~min}$ for which the contributions to average convection would be $(\Delta F / \Delta \tau)=56$ and $14 \mathrm{kV}$ (for the emission altitudes of 500 and $250 \mathrm{~km}$, respectively).

These estimates may be either increased or decreased depending on our choice of 630-nm isophote which delineates the event and hence are highly approximate. This uncertainty arises from locating the edge of the event with an assumed single emission altitude when in practice the light comes from a range of altitudes, as discussed in section 2.3. However, these calculations illustrate the importance of knowing the peak emission altitude if not the full emission profile. The value of $14 \mathrm{kV}$ derived for the lower altitude of $250 \mathrm{~km}$ is only about $10 \%$ of the voltage observed across the polar cap during strongly southward IMF. However, the voltage of $56 \mathrm{kV}$ derived for the higher emission altitude is about half this typical value. Hence the questions about the importance of these events for convection call for accurate determination of the altitude profile of emission. The corresponding value for the January 12, 1988, event is well defined by the joint optical/radar observations to be around $25 \mathrm{kV}$.

It is interesting to compare these values with those for events recently reported by Sandholt et al. [1992a]. These events were smaller (and hence could be fully imaged by the CCD camera) but were repeated with an average period of 9 min. Assuming an emission altitude of $250 \mathrm{~km}$, these authors derived event dimensions of $200 \mathrm{~km}$ north-south by $300 \mathrm{~km}$ east-west. For these values the average contribution to convection is just $4 \mathrm{kV}$. This would rise to a maximum of 20 $\mathrm{kV}$ if the $630-\mathrm{nm}$ emission were in fact from an altitude of 550 $\mathrm{km}$.

\section{Conclusions}

We have examined two dayside auroral transients and associated flow burst events. Although both have been previously published, we have examined them more critically here for the purpose of making three important points.

The first point is to verify the symmetric consistency of our electrodynamic description of the transient events. In both eastward and westward propagating cases, the 557.7-nm transient (produced by energized electron impact excitation) is a latitudinally narrow feature colocated with the inferred transient upward field-aligned current. This means for these northern hemisphere events that the $557.7-\mathrm{nm}$ transient lies on the equatorward edge of the flow burst and the 630-nm transient for the eastward moving event but on their poleward edge for the westward moving event. The flow burst and $630-\mathrm{nm}$ transient are colocated in both cases and the plasma flow within the burst, as deduced from the radar observations of ion temperature and line-ofsight velocity, has been shown to be very similar to the auroral event motion.

The observations support the theoretical description of these events, put forward by Cowley et al. [1991] and Smith et al. [1992]. This is based on the concepts of flow excitation and decay developed by Cowley and Lockwood [1992]. The occurrence of reconnection bursts causes periodic motions of the merging gap location, but strong (and zonal) flow bursts only if the IMF $B_{y}$ component is large in magnitude. Periodic reconnection events, with the same spacing as magnetopause FTEs, could give rise to almost steady poleward flows, and these would be the only flows were the IMF $B_{y}$ small. These concepts were also used by Lockwood and Smith [1989] to explain cusp ion dispersion in terms of FTE signatures. The merging gap motions would be typically $1-3^{\circ}$, which is well within the scatter of the observed latitude of the equatorward boundary of the cusp, as presented in the statistical survey by Newell et al. [1989].

The third conclusion relates to the significance of the altitude of the 630 -nm emission. For the above description the importance of these transient events to the overall ionospheric and magnetospheric convection (as quantified by the transpolar voltage), is in simple proportion to both their area and their repetition frequency. For the given angular extent seen from the ground, the area that the transient $630-n m$ luminosity covers is proportional to the square of the emission altitude. Past work and interpretation has adopted a nominal altitude of $250 \mathrm{~km}$ for the $630-\mathrm{nm}$ emission. We present here an argument that some $630-\mathrm{nm}$ transient events occur at twice this height. We also show here that of the two events considered here one indeed arose from at least $400 \mathrm{~km}$, and possibly $500 \mathrm{~km}$ or higher. We conclude that these transient events thus may be significantly more important to polar convection than previously suggested and that determination of the $630-\mathrm{nm}$ emission altitude is vital for quantifying their role. We also note that for most events, the full longitudinal extent is not well known, because of the low camera sensitivity at large zenith angles. Observations from a longitudinal chain of such cameras may call for a further upward revision of the contribution of these events to convection. At times, transient reconnection events could therefore be the primary driving mechanism for convection.

Last, we note that the westward moving event studied here was consistent with the $630-\mathrm{nm}$ emission from $250 \mathrm{~km}$ altitude and gave considerable 557.7-nm emission. Conversely, the eastward moving event was consistent with a $630-\mathrm{nm}$ emission altitude of nearer $500 \mathrm{~km}$ and was associated with a relatively weak and short-lived 557.7 -nm transient. Specifically, the 557.7-nm transient colocated with the upward transient current in the westward moving event was much stronger, and some 557.7-nm emission was detected within the $630-\mathrm{nm}$ transient. The higher value of the $I(557.7$ $\mathrm{nm}) / I(630 \mathrm{~nm})$ intensity ratio inside the event indicates that the precipitating electron spectrum is somewhat harder for the January 12, 1988, event. It is not clear from this study whether this difference is related to the sense of motion of the two events (and hence the IMF $B_{y}$ polarity), or to other factors. One possibility is that the Alfvén speed at the magnetopause was different for these two events. This determines the speed with which newly opened field lines move along the magnetopause and hence the acceleration of magnetopause ions which enter along the field lines. It is possible that the subsequent ion time-of-flight characteristics influence the electron precipitation by the weak ambipolar electric fields which maintain the observed quasi-neutrality 
in the cusp region. Such ideas call for considerable further study, both experimental and theoretical. However, it does appear that relatively few eastward moving transient events have been observed using the 557.7-nm ISIT camera [Sandholt, 1988], whereas they are readily observed using the 630-nm CCD camera [Lockwood et al., 1990c; Sandholt et al., 1990a; Sandholt et al., 1992a]. This suggests that the differences in the intensity of the main $557.7-\mathrm{nm}$ transient on the edge of the 630-nm transient (as opposed to those in the low-level $557.7-\mathrm{nm}$ emission within the $630-\mathrm{nm}$ transient) may indeed be related to an asymmetry with respect to the IMF $B_{y}$ component. The reasons for any such asymmetry are not known. We note that the region of the upward field-aligned current (where the main $557.7-\mathrm{nm}$ transient is observed) maps magnetically to the subsolar LLBL for IMF $B_{y}<0$ (for northern hemisphere events) whereas it maps to the mantle region for $B_{y}>0$. This may give a different source population for electron current carriers. We also note that the current contribution of upwelling ionospheric ions in the cleft ion fountain may introduce an asymmetry between these two cases.

Acknowledgments. This work was partially supported by an AFOSR Window on Europe Award and AFOSR task 2310G9. The authors thank V. N. Davda for help with the color graphics. We thank the director and staff of the EISCAT Scientific Association for their assistance.

The Editor thanks J. Kozyra and a second referee for their assistance in evaluating this paper.

\section{REFERENCES}

Berchem, J., and C. T. Russell, Flux transfer events on the magnetopause: Spatial distribution and controlling factors, $J$. Geophys. Res., 89, 6689-6703, 1984.

Brace, L. H., R. F. Theis, and W. R. Hoegy, A global view of the $F$ region electron density and temperature at solar maximum, Geophys, Res. Lett., 9, 989-992, 1982.

Cowley, S. W. H., and M. Lockwood, Excitation and decay of Solar wind-driven flows in the magnetosphere-ionosphere system, Ann. Geophys., 10, 103-115, 1992.

Cowley, S. W. H., M. P. Freeman, M. Lockwood, and M. F. Smith, The ionospheric signature of flux transfer events, in "CLUSTER-Dayside Polar Cusp," edited by C. I. Barron, European Space Agency Publications, Nordvijk. The Netherlands, Eur. Space Agency Spec. Publ. SP-330, pp. 105-112, 1991.

Elphic, R. C., Multipoint observations of the magnetopause: Results from ISEE and AMPTE, Adv. Space Res., 8(9), 223-238, 1988.

Elphic, R. C., M. Lockwood, S. W. H. Cowley, and P. E. Sandholt, Signatures of flux transfer events at the dayside magnetopause and in the ionosphere: Combined ISEE, EISCAT, and optical observations, Geophys. Res. Lett., 17, 2241-2244, 1990.

Farrugia, C. J., R. C. Elphic, D. J. Southwood, and S. W. H. Cowley, Field and flow perturbations outside the reconnected field line region in flux transfer events: Theory, Planet. Space Sci., 35, 227-240, 1987a.

Farrugia, C. J., D. J. Southwood, S. W. H. Cowley, R. P. Rijnbeek, and P. W. Daly, Two-regime flux transfer events, Planet. Space Sci., 35, 737-744, $1987 b$.

Farrugia, C. J., R. P. Rijnbeek, M. A. Saunders, D. J. Southwood, D. J. Rodgers, M. F. Smith, C. P. Chaloner, D. S. Hall, P. J. Christiansen, and L. J. C. Woolliscroft, A multi-instrument study of flux transfer event structure, J. Geophys. Res., 93, 14,46514,477, 1988.

Fontheim, E. G., L. H. Brace, and J. D. Winningham, Properties of low-energy electron precipitation in the cleft during periods of unusually high ambient electron temperature, J. Geophys. Res., $92,12,267-12,273,1987$

Haerendel, G., G. Paschmann, N. Sckopke, H. Rosenbauer, and P. C. Hedgecock, The frontside boundary layer of the magneto- pause and the problem of reconnection, J. Geophys. Res., 83, 3195-3216, 1978.

Kozyra, J. V., C. E. Valladares, H. C. Carlson, M. J. Buonsanto, and D. W. Slater, A theoretical study of the seasonal and solar cycle variations of stable auroral red arcs, J. Geophys. Res., 95, $12,219-12,234,1990$

Lockwood, M., Flux transfer events at the dayside magnetopause: Transient reconnection or magnetosheath pressure pulses?, $J$. Geophys, Res., 96, 5497-5509, 1991.

Lockwood, M., and S. W. H. Cowley, Ionospheric convection and the substorm cycle, in Proceedings of the First International Conference on Substorms (ICS-1), European Space Agency Publications, ESTEC, Nordvijk, The Netherlands, Eur. Space Agency Spec. Publ. ESA-SP-335, pp. 117-123, 1992.

Lockwood, M., and M. F. Smith, Low altitude signatures of the cusp and flux transfer events, Geophys. Res. Lett., 16, 879-882, 1989.

Lockwood, M., and M. F. Smith, The variation of reconnection rate at the dayside magnetopause and cusp ion precipitation, $J$. Geophys. Res., 97, 14,841-14,847, 1992.

Lockwood, M., and M. N. Wild, On the quasi-periodic nature of magnetopause flux transfer events, J. Geophys. Res., 98, 5935$5940,1993$.

Lockwood, M., and K. J. Winser, On the determination of ion temperature in the auroral F-region ionosphere, Planet Space Sci, 36, 1295-1304, 1988.

Lockwood, M., P. E. Sandholt, and S. W. H. Cowley, Dayside auroral activity and magnetic flux transfer from the solar wind, Geophys. Res, Lett., I6, 33-36, 1989a.

Lockwood, M., P. E. Sandholt, S. W. H. Cowley, and T. Oguti, Interplanetary magnetic field control of dayside auroral activity and the transfer of momentum across the dayside magnetopause, Planet. Space Sci., 37, 1347-1365, $1989 \mathrm{~b}$.

Lockwood, M., K. Suvanto, K. J. Winser, S. W. H. Cowley, and D. M. Willis, Incoherent scatter radar observations of nonMaxwellian ion velocity distributions in the auroral $F$ region, $A d v$. Space Res., 9(5)113-(5)118, 1989C.

Lockwood, M., S. W. H. Cowley, and P. E. Sandholt, Transient reconnection-The search for ionospheric signatures, Eos, Trans. $A G U, 71(20), 709-720,1990 a$.

Lockwood, M., S. W. H. Cowley, P. E. Sandholt, and R. P. Lepping, The ionospheric signatures of flux transfer events and solar wind dynamic pressure changes, J. Geophys. Res., 95, $17,113-17,135,1990 b$.

Lockwood, M., P. E. Sandholt, A. D. Farmer, S. W. H. Cowley, B. Lybekk, and V. N. Davda, Auroral and plasma flow transients at magnetic noon, Planet. Space Sci., 38, 973-993, $1990 \mathrm{c}$.

Mantas, G. P., and J. C. G. Walker, The penetration of soft electrons into the ionosphere, Planet. Space Sci., 24, 409-423, 1976.

Newell, P. T., C.-I. Meng, D. G. Sibeck, and R. Lepping, Some low-altitude cusp dependencies on the interplanetary magnetic field, J. Geophys. Res., 94, 8921-8927, 1989.

Paschmann, G., G. Haerendel, I. Papamastorakis, N. Sckopke, S. J. Bame, J. T. Gosling, and C. T. Russell, Plasma and magnetic field characteristics of magnetic flux transfer events, J. Geophys. Res., $87,2159-2168,1982$.

Rees, M. H., and R. G. Roble, Excitation of the $O\left({ }^{1} D\right)$ atoms in

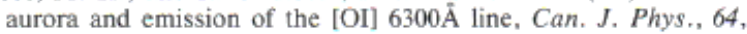
$1608-1613,1986$.

Rijnbeek, R. P., S. W. H. Cowley, D. J. Southwood, and C. T. Russell, A survey of dayside flux transfer events observed by the ISEE 1 and 2 magnetometers, J. Geophys. Res., 89, 786-800, 1984.

Russell, C. T., and R. C. Elphic, Initial ISEE magnetometer results: Magnetopause observations, Space Sci. Rev., 22, 681-715, 1978.

Russell, C. T., and R. C. Elphic, ISEE observations of flux transfer events at the dayside magnetopause, Geophys. Res. Lett., 6, 33-36, 1979.

Sandholt, P. E., IMF control of the polar cusp and cleft auroras, Adv. Space Res., 8(9)21-(9)34, 1988.

Sandholt, P. E., A. Egeland, J. A. Holtet, B. Lybekk, K. Svenes, and S. Asheim, Large- and small-scale dynamics of the polar cusp, J, Geophys, Res, , 90, 4407-4414, 1985.

Sandholt, P. E., B. Lybekk, A. Egeland, B. Jacobson, P. F. Bythrow, and D. A. Hardy, Electrodynamics of the polar cusp 
ionosphere-A case study, J. Geophys. Res., 94, 6713-6722. $1989 a$.

Sandholt, P. E., B. Lybekk, A. Egeland, R. Nakamura, and T. Oguti, Midday auroral breakup, J. Geomagn. Geoelectr., 4I, 371-387, 1989b.

Sandholt, P. E., M. Lockwood, B. Lybekk, and A. D. Farmer, Auroral bright spot sequence near 1400 MLT: Coordinated optical and ion drift observations, J. Geophys. Res., 95, 21,095-21,110, $1990 a$.

Sandholt, P. E., M. Lockwood, T. Oguti, S. W. H. Cowley, K. S. C. Freeman, B. Lybekk, A. Egeland, and D. M. Willis, Midday auroral breakup events and related energy and momentum transfer from the magnetosheath, J. Geophys. Res., 95, 1039-1060, $1990 b$.

Sandholt, P. E., J. Moen, and D. Opsvik, Periodic auroral events at the midday polar cap boundary: implications for solar windmagnetosphere coupling, Geophys, Res. Lett., 19, 1223-1226, $1992 a$.

Sandholt, P. E., M. Lockwood, W. F. Denig, R. C. Elphic, and S. Leontjev, Dynamical auroral structure in the vicinity of the polar cusp: Multipoint observations during southward and northward IMF, Ann. Geophys, , 10, 483-497, $1992 b$.

Sibeck, D. G., A model for the transient magnetospheric response to sudden solar wind dynamic pressure variations, J. Geophys. Res., 95, 3755-3771, 1990 .

Sibeck, D. G., Transient magnetic field signatures at high latitudes, J. Geophys. Res., 98, 243-256, 1993.

Siscoe, G. L., and T. S. Huang, Polar cap inflation and deflation, $J$. Geophys. Res., 90, 543-547, 1985

Smith, M. F., and M. Lockwood, The pulsating cusp, Geophys. Res. Lett., 17, 1069-1072, 1990.
Smith, M. F., M. Lockwood, and S. W. H. Cowley, The statistical cusp: A flux transfer event model, Planet. Space Sci., 40, 1251-1268, 1992.

Stömer, C., The Polar Aurora, Clarendon, Oxford, 1955.

Suvanto, K., M. Lockwood, K. J. Winser, A. D. Farmer, and B. J. 1. Bromage, Analysis of incoherent scatter radar data from non-thermal F-region plasma, J. Atmos. Terr. Phys., 51, 483-495, 1989.

Tereshchenko, V. D., E. A. Tereshchenko, and H. Kohl, The incoherent scattering of radio waves in a non-Maxwellian plasma: The effect of Couloumb collisions, J. Geophys. Res., 96, 17,591, 1991.

Wickwar, V. B., and W. Kofman, Dayside red auroras at very high latitudes: The importance of thermal excitation, Geophys. Res, Lett., II, 923-926, 1984.

Wickwar, V. B., L. L. Cogger, and H. C. Carlson, The $6300 \AA ̊$ O $\left({ }^{1} \mathrm{D}\right)$ airglow and dissociative recombination, Planet. Space Sci., 22, $709-724,1974$.

H. C. Carlson, Jr., Phillips Laboratory, Hanscom Air Force Base, Bedford, MA 01731.

M. Lockwood, Rutherford Appleton Laboratory, Space Science Department, Chilton, Didcot, OX11 0QX, England.

P. E. Sandholt, Department of Physics, University of Oslo, Box 1048, Blindern 0316, Oslo 3, Norway.

(Received May 11, 1992:

revised February 10, 1993;

accepted March 23, 1993.) 